\title{
Le site de plein air de Mirande 2 (Vaïssac, Tarn- et-Garonne) : un nouveau jalon badegoulien en Bas-Quercy
}

The open-air site of Mirande 2 (Vaïssac, Tarn-et-Garonne) : a new Badegoulian site in the lower Quercy region

Mathieu Langlais, Sylvain Ducasse, Luca Sitzia, Guilhem Constans, Pierre Chalard, Jean-Philippe Faivre, François Lacrampe-Cuyaubère et Xavier Muth

\section{OpenEdition}

\section{Journals}

Édition électronique

URL : http://journals.openedition.org/paleo/3132

DOI : $10.4000 /$ paleo.3132

ISSN : $2101-0420$

Éditeur

SAMRA

Édition imprimée

Date de publication : 30 décembre 2016

Pagination : 207-233

ISSN : $1145-3370$

Référence électronique

Mathieu Langlais, Sylvain Ducasse, Luca Sitzia, Guilhem Constans, Pierre Chalard, Jean-Philippe Faivre, François Lacrampe-Cuyaubère et Xavier Muth, « Le site de plein air de Mirande 2 (Vaïssac, Tarn-et-Garonne) : un nouveau jalon badegoulien en Bas-Quercy », PALEO [En ligne], 27 | 2016, mis en ligne le 01 juin 2018, consulté le 07 juillet 2020. URL : http://journals.openedition.org/paleo/3132 ; DOI : https://doi.org/10.4000/paleo.3132

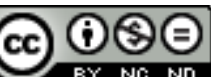

PALEO est mis à disposition selon les termes de la licence Creative Commons Attribution - Pas d'Utilisation Commerciale - Pas de Modification 4.0 International. 


\title{
Le site de plein air de Mirande 2 (Vaïssac, Tarn-et-Garonne) : un nouveau jalon badegoulien en Bas-Quercy
}

\author{
Mathieu LANGLAIS ${ }^{(a, b)}$, Sylvain DUCASSE(a), Luca SITZIA ${ }^{(0)}$, \\ Guilhem CONSTANS ${ }^{(\mathrm{d})}$, Pierre CHALARD $^{(\mathrm{d})}$, Jean-Philippe FAIVRE ${ }^{(\mathrm{a})}$, \\ François LACRAMPE-CUYAUBËRE ${ }^{(e)}$, Xavier MUTH(e)
}

\begin{abstract}
Résumé : Le gisement de plein air de Mirande 2 a été récemment découvert sur la commune de Vaïssac (Tarn-etGaronne), à une centaine de mètres du site de Mirande 1 fouillé entre 1971 et 1976 par R. Guicharnaud à Nègrepelisse. Cette opération de sondage préventif a permis d'évaluer les potentialités du site, d'en proposer une contextualisation géologique précise et d'exhumer les divers éléments de diagnose présentés ici. Mirande 2 est implanté sur un léger replat en rive gauche de l'Aveyron. Les trois secteurs de fouille (Tranchée Sud, Coupe Nord et Sondage) ont exclusivement livré des vestiges lithiques (silex et quartz) dont les caractéristiques typo-technologiques sont constantes d'une zone à l'autre et forment un ensemble cohérent sur le plan chronoculturel. Les premières observations archéostratigraphiques indiquent l'existence d'une concentration principale plus ou moins dilatée selon les secteurs. Les vestiges, dont les caractéristiques technotypologiques permettent d'attribuer l'ensemble au Badegoulien, se répartissent en différents types de supports et matières premières. Quelques blocs de trachyte façonnés et des galets de quartz débités proviennent vraisemblablement de la paléo-terrasse sur laquelle se sont installés les groupes humains. Les quartz sont présents sous la forme de macro-outils ou débités pour obtenir des éclats. L'essentiel des silex abandonnés sur le site provient des terrasses de la Vère et de l'Aveyron. Quelques indices tendraient également à montrer un apport de volumes en silex allochtones sur près de $100 \mathrm{~km}$ depuis le nord. En revanche, les autres matériaux allochtones sont présents sous la forme d'outils, signant vraisemblablement une fin de cycle fonctionnel. Du point de vue des supports d'outils à vocation domestique, on note une double composante. Des grattoirs, outils multiples et pièces à retouches latérales sont réalisés sur lame et éclats laminaires. Pour cette composante, et en l'état de l'analyse, l'hypothèse de deux schémas opératoires peut être proposée : une production laminaire cintrée et un débitage de supports envahissants sur face large. D’autres outils (racloirs, raclettes) sont réalisés sur éclats résultant de diverses chaînes opératoires parfois autonomes. Les microlithes sont composés de lamelles et micro-lamelles à dos de différents types et dont les supports sont produits à partir de rognons et éclats selon différentes modalités. Si le gisement de Mirande 2 constitue un nouveau témoignage d'occupations de plein air sur la paléo-terrasse de l'Aveyron, à proximité de sa confluence avec le Gouyré, il offre avant tout l'un des premiers jalons badegouliens entre Languedoc et Quercy, dans une région où il était peu connu jusqu'alors.
\end{abstract}

Mots-clés : Badegoulien, plein air, Quercy, pétroarchéologie, technologie lithique, silex, quartz.

(a) CNRS Laboratoire PACEA UMR 5199, Univ. Bordeaux, Allée Geoffroy Saint-Hilaire CS 50023, FR-33615 Pessac cedex mathieu.langlais@u-bordeaux.fr ; sylvain.ducasse@u-bordeaux.fr ; jean-philippe.faivre@u-bordeaux.fr

(b) SERP, universitat de Barcelona, Gran Via de Les Corts Catalanes, 585, SP-08007 Barcelona,

(c) Universidad de Tarapacá, Instituto de Alta Investigación Laboratorio de Análisis e Investigaciones Arqueométricas Antofagasta 1520

1010069 Arica, Chile - Icsitzia@gmail.com

(d) Laboratoire TRACES UMR 5608, UT2J, MCC, Maison de la Recherche 5 allée Antonio Machado FR-31058 Toulouse cedex 9 -

guilhem.contans@hotmail.fr ; pierre.chalard-biberson@culture.gouv.fr

(e) SARL Get In Situ, 7 rue de la gare, CH-1091 Grandvaux - f.lacrampe@archeosphere.com ; xavier.muth@gmail.com 


\begin{abstract}
The open-air site of Mirande 2 (Vaïssac, Tarn-et-Garonne): a new Badegoulian site in the lower Quercy region. The recently discovered open-air site of Mirande 2 (Vaïssac, Tarn-et Garonne) lies on a gentle incline of the left bank of the Aveyron River approximately 100 metres from the site of Mirande 1 (Nègrepelisse, Tarn-et-Garonne), which was excavated between 1971 and 1976 by R. Guicharnaud. A test-pit carried out during rescue work evaluated the site's potential, provided important geological and produced diagnostic archaeological material. The three excavated sectors (South Trench, North Section and Test-Pit) preserved only lithic material (flint and quartz), whose typo-technological composition evinces a chrono-culturally coherent assemblage. Initial archaeo-stratigraphic information indicates a single concentration of archaeological material that varies in thickness by sector. Attributable to the Badegoulian, the lithic assemblage comprises various blanks and multiple types of raw materials. Several shaped trachyte blocks and quartz pebbles, exploited for the production of heavy-duty tools and flakes, likely derive from the paleo-terrace occupied by the human groups. While the majority of the flint artefacts come from the terraces of the Vère and Aveyron Rivers, a limited quantity of non-local raw materials were introduced from sources some $100 \mathrm{~km}$ to the north. These latter artefacts are found uniquely as tools that were likely discarded at the end of their use-lives. Two types of domestic tool blanks were identified; endscrapers, combination tools and laterally retouched pieces on blades and elongated flakes alongside scrapers and raclettes on flakes produced according to different, sometimes independent chaînes opératoires. In terms of the blade and elongated flake component, our preliminary analysis suggests blanks to have been detached from either a wide surface or from wedge-shaped cores. Finally, microliths are represented by different types of backed microbladelets on blanks produced from nodules and flakes. In addition to Mirande 2 being a new open-air occupation on the paleo-terraces of the Aveyron River near its confluence with the Gouyré, it also amongst the first evidence for the Badegoulian between the Lanquedoc and Quercy regions in an area where this culture remained poorly documented.
\end{abstract}

Key-words: Badegoulian, open air site, Quercy, Petroarchaeology, Lithic Technology, Flint, Quartz.

\section{Introduction}

Les marges méridionales du Bas-Quercy forment un domaine bien connu pour ses grottes et abris du Paléolithique récent (fig. 1a). La basse vallée de l'Aveyron est en effet jalonnée de gisements parmi lesquels on peut citer les célèbres abris magdaléniens de Bruniquel Plantade, Lafaye, Gandil, Montastruc - (Tarn-et-Garonne), la grotte du Courbet (Penne, Tarn) ou encore l'abri Fontalès (Saint-Antonin-Noble-Val, Tarn-et-Garonne) (e.g. Pajot 1969). Si le Tardiglaciaire du Montalbanais est ainsi abondamment documenté - bien que sous la forme de séries partielles (fouilles anciennes de V. Brun, M. Chaillot ou B. Bétirac notamment) - on constate un très faible nombre d'occupations contemporaines de la fin du dernier Pléniglaciaire. Ce vide documentaire a été en partie comblé grâce à la mise au jour, dans les années 1990, d'un ensemble attribuable au Magdalénien inférieur (ca21-19 ka cal. BP) au sein de la stratigraphie basse de l'abri Gandil (Ladier 1995, 2000 ; Langlais et al. 2007 ; Ladier dir. 2014). En revanche, le Badegoulien (ca 23-21 ka cal. BP), pourtant bien documenté dans le bassin versant du Lot (e.g. Abri du Cuzoul à Vers : Clottes, Giraud, Chalard dir. 2012 ; Les Peyrugues à Orniac : Allard 2009 ; Grotte de Pégourié à Caniac-du-Causse : Séronie-Vivien dir. 1995 ; Le Petit Cloup Barrat à Cabrerets : Castel et al. 2005), n'était jusqu'ici connu en Bas-Quercy qu'à travers quelques séries de surface (e.g. Lasgardes-Haut à Granejouls : fig. $1 \mathrm{a}, \mathrm{n}^{\circ} 12$, Coucounès à Lapenche : $\mathrm{n}^{\circ} 11$, voire la Plaine d'Esandérou au Verdier : $n^{\circ} 9$; Le Brun-Ricalens 1988 ; Morala 2013) ${ }^{1}$. Au sein de ce maigre corpus, le gisement de plein air de Mirande (Nègrepelisse, Tarn-etGaronne) se distingue non seulement par l'abondance du matériel et la qualité de l'information qu'il a livré (fouilles R. Guicharnaud), mais également pour les débats qu'il génère autour de son attribution chronoculturelle (voir infra). En 2014, une opération de sondages préventifs menée sur une parcelle voisine de celle qu'avait explorée R. Guicharnaud au début des années 1970 a livré un assemblage lithique rapportable selon toutes vraisemblances au Badegoulien (Langlais coord. 2014). Cette découverte, dont les résultats préliminaires font l'objet du présent article, permet de rediscuter de l'attribution de l'industrie de Mirande près de 90 ans après sa découverte et, ce faisant, éclaire sous un jour nouveau la question de l'occupation humaine bas-quercinoise durant la fin du dernier Pléniglaciaire.

\section{1 - Le site de Mirande 1 : rappel des faits}

Découverte en 1928 lors de ramassages de surface puis sondée dans les années 1930 (Bergougnoux et Chaillot 1933), la station d'abord dite de «Montricoux » a livré plusieurs collections dont la plus grande part est aujourd'hui

(1) La révision de la collection lithique du site de Pénovaire (Penne, Tarn ; MNHN de Toulouse, ML et SD obs. pers.), pour lequel B. Pajot signalait la présence de raclettes «très typiques " tout en attribuant l'assemblage au Magdalénien moyen (1968 - p. 88), a permis d'écarter toute possibilité de Badegoulien sur ce site, les « raclettes » observées ne correspondant vraisemblablement qu'à de simples éclats retouchés. 

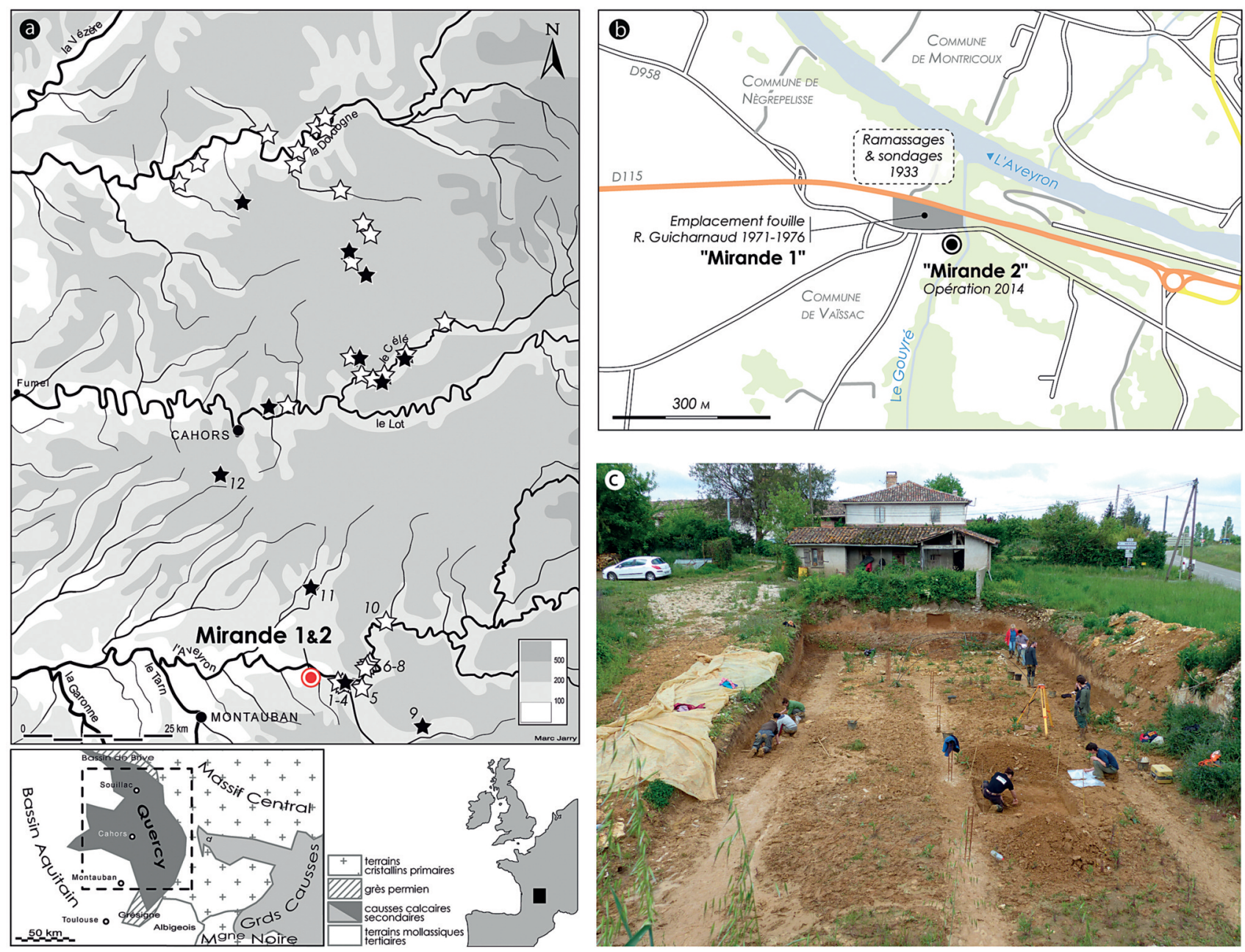

Figure 1 - Le site de Mirande dans son contexte régional et local. a : Localisation des principaux sites quercinois datant de la fin du Pléniglaciaire (étoiles noires) et du Tardiglaciaire (étoiles blanches); $n^{\circ} 1$ à 4 : Plantade, Lafaye, Gandil et Montastruc, $n^{\circ} 5:$ Abri du Cambou, $n^{\circ} 6$ à 8 : Pénovaire, Le Courbet, La Madeleine-des-Albis, $n^{\circ} 9$ : Plaine d'Esandérou, $n^{\circ} 10$ : Fontalès, $n^{\circ} 11$ : Coucounès, $n^{\circ}$ 12 : Lasgardes-Haut (fond de carte M. Jarry, INRAP) / $b$ : Plan de situation du gisement et localisation des différents locus et interventions menées entre 1933 et 2014 (fond de carte d'après Géoportail, modifié) / c : Vue générale de Mirande 2 en cours de fouille (cliché P. C.).

Figure 1 - Regional and local context of Mirande. a: Location of the main Upper Pleniglacial (black stars) and Late Glacial (white stars) sites in the Quercy region; $n^{\circ} 1$ to 4: Plantade, Lafaye, Gandil and Montastruc, $n^{\circ} 5$ : Abri du Cambou, $n^{\circ} 6$ à 8: Pénovaire, Le Courbet, La Madeleine-des-Albis, $n^{\circ}$ 9: Plaine d'Esandérou, $n^{\circ}$ 10: Fontalès, $n^{\circ} 1$ 1: Coucounès, $n^{\circ} 12$ : Lasgardes-Haut (map M. Jarry, INRAP) / b: Site context and location of the different sectors and test-pits carried out between 1933 and 2014 (map modified after Géoportail) / c: General view of the site during excavations (photo P. C.). 
perdue $^{2}$. Suite à de nouvelles prospections (Pajot 1968) ouvrant sur une fouille extensive de près de $60 \mathrm{~m}^{2}$ menée par R. Guicharnaud dans les années 1970, le gisement prend l'appellation de « Mirande »-du nom du lieu-dit le plus proche - et le locus fouillé, situé entre les routes D958 et D115 (fig. 1b) devient « Mirande 1 » (Guicharnaud 19711974, 1976a, 1976b). Plusieurs hypothèses d'attribution culturelle ont été proposées pour ce riche assemblage composé presque exclusivement de vestiges lithiques, et pour lequel aucune datation ${ }^{14} \mathrm{C}$ fiable n'a pu être effectuée $^{3}$. Tandis que les premiers fouilleurs parlent d'Aurignacien " inférieur » (cf. Châtelperronien) et de Moustérien, B. Pajot propose d'attribuer la série au Gravettien sur la base de critères typologiques aujourd'hui discutables (Pajot 1968 - p. 288-291 : rapport de proportions entre burins et grattoirs, fréquence des burins sur troncature et présence de burins plans rappelant les «burins du Raysse »; pour une critique détaillée voir MilletConte 1994 - p. 46-49). À partir du produit de ses fouilles menées à Mirande 1, R. Guicharnaud rapproche l'assemblage du Magdalénien final, proposition notamment étayée par l'existence d'un outil interprété comme un burin bec-de-perroquet (Guicharnaud 1971-1974 - p. 6). Tout en réfutant cette dernière attribution typologique, ce diagnostic chronoculturel sera repris et complété à l'occasion d'une étude technologique menée dans le cadre d'un mémoire universitaire (Millet-Conte 1994). Cet auteur, prenant pour base un échantillon de cette très riche industrie, s'appuiera sur l'abondance des lamelles à dos, la prépondérance des burins dièdres sur les burins sur troncature, la présence de pièces interprétées comme des pointes à cran magdaléniennes, mais aussi sur l'importance des grattoirs plutôt courts qui annonceraient selon lui l'Azilien (op. cit., p. 53-57).

II faudra attendre plus de dix ans pour que de nouvelles études voient le jour sous la conduite de G. Bosinski qui, à partir des années 2000, entreprend une réévaluation de l'ensemble de la collection Guicharnaud. Après l'analyse des quartz - très abondants à Mirande 1 - qui l'ont conduit à proposer la mise en œuvre d'un débitage bipolaire sur enclume (Bosinski et Guicharnaud 2008), une étude détaillée des très nombreux microlithes récoltés lors de la fouille ainsi que des modalités de production de leurs supports le conduit à revoir l'attribution de cet ensemble et, par comparaison avec plusieurs séries à microlamelles à dos décrites depuis les Cantabres jusqu'au Sud-Ouest français (e.g. Cazals 2000 ; Ladier 2000 ; Langlais 2007), propose d'attribuer l'industrie au Magdalénien inférieur (Bosinski 2013).

\section{2 - L'apport de Mirande 2}

En avril 2014, grâce à la vigilance d'Edmée Ladier, le Service Régional de l'Archéologie Midi-Pyrénées est informé de la présence d'artefacts lithiques affleurant en surface et en coupe au niveau d'une parcelle en construction située en face de Mirande 1, de l'autre côté de la D958 (fig. 1b). Cette fois localisés sur la commune de Vaïssac, ces indices archéologiques ont alors été consignés sous l'appellation de «Mirande 2 ». Dans l'hypothèse que ces vestiges matérialisaient la continuité du même gisement, cette découverte offrait a minima l'occasion de mieux contextualiser les occupations humaines de Mirande. Une opération de sauvetage a donc été menée quelques semaines après la découverte (Langlais coord. 2014, 2015). Le chantier a été implanté au sein de l'excavation rectangulaire réalisée par le propriétaire pour y construire une habitation dont les fondations linéaires étaient déjà en place (fig. 1c). En dehors des ramassages effectués en surface, les travaux ont porté sur trois secteurs principaux et disjoints, correspondant aux différentes coupes dégagées pour un total d'environ $15 \mathrm{~m}^{2}$ (fig. 2 : "Tranchée sud », " Coupe nord » et "Sondage »). Les tests de tamisage effectués durant la fouille se sont révélés trop chronophages du fait de la nature très argileuse du sédiment et au regard du temps/homme imparti pour l'opération ${ }^{4}$. Nous avons donc privilégié, pour chaque secteur, la cotation 3D d'un maximum d'objets, tandis que des prélèvements « en masse " par tranche de 2 à $5 \mathrm{~cm}$ ont été réalisés au sein d'une colonne test implantée au niveau du Sondage afin de procéder à leur tamisage en laboratoire.

Les lignes qui suivent présentent les principaux apports de cette opération, tant sur le plan contextuel (géologie et stratigraphie, degré de préservation du niveau archéologique) que sur la nature, l'homogénéité et l'attribution chronoculturelle des éléments mis au jour.

\section{1 - Contexte géologique, stratigraphie des dépôts et taphonomie}

Localisé en rive gauche de l'Aveyron, Mirande 2 se situe sur un léger replat qui s'élève d'environ $6 \mathrm{~m}$ par rapport au lit actuel de la rivière. D'après la carte géologique, ce replat correspond à la plus basse terrasse de l'Aveyron (Fy2) dont l'âge serait Würm ancien (fig. $3 a$; Astruc et al. 2000). Dans le secteur, le système de terrasses structure le paysage tandis que, quelques kilomètres en amont, la vallée se rétrécie nettement et les terrasses ne subsistent que sous

(2) Seules les pièces collectées par M. de Maulde, rachetées par le Colonel Vésinié puis léguées à l'Institut de Paléontologie Humaine, restent aujourd'hui consultables. II semble en revanche que la série collectée par Bergougnoux et Chaillot ait disparu (Millet-Conte 1994 - p. 21).

(3) Après une tentative infructueuse menée en collaboration avec Gif-sur-Yvette (Millet-Conte 1994 - p. 52-53), deux os ont été soumis au laboratoire de Lyon (CDRC-Artemis) pour datation AMS dans le cadre du PCR SaM (Ducasse et Renard coord., 2013). Les faibles taux de collagène n'ont pas permis l'obtention de ces mesures. En 2015, un essai sur charbons coordonnés dans le niveau, réalisé par le laboratoire d'Oxford (ORAU), a livré un résultat aberrant (OxA-33216: $45300 \pm 1900 \mathrm{BP})$.

(4) L'opération s'est en effet déroulée sur trois jours, du 28 au 30 avril 2014, mobilisant un total de 36 journées-hommes. 


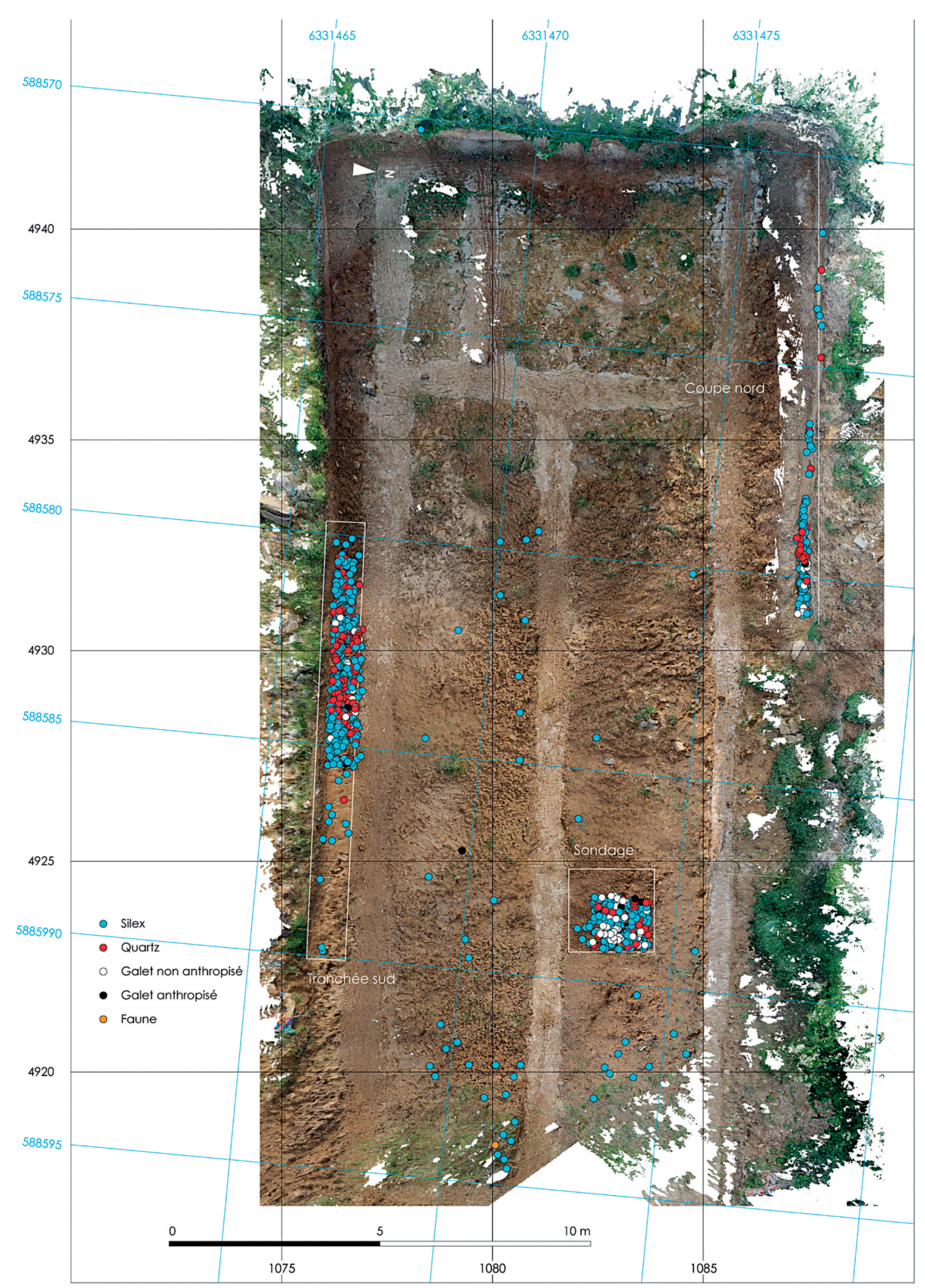

Figure 2 - Orthophotographie du gisement de Mirande 2, détail des trois secteurs fouillés et projection en plan des pièces coordonnées. Notons la mise en relation entre la grille Lambert 93 (en bleu, calage obtenu par DGPS) et la grille utilisée pour établir les projections du matériel archéologique (DAO Get In Situ).

Figure 2 - Orthophoto of Mirande 2, the three excavated sectors and horizontal projection of piece-plotted artefacts. Note the correlation with the Lambert 93 system (in blue, relation established using DGPS) and grid system for projection of archaeological material (IIlustration Get In Situ). 


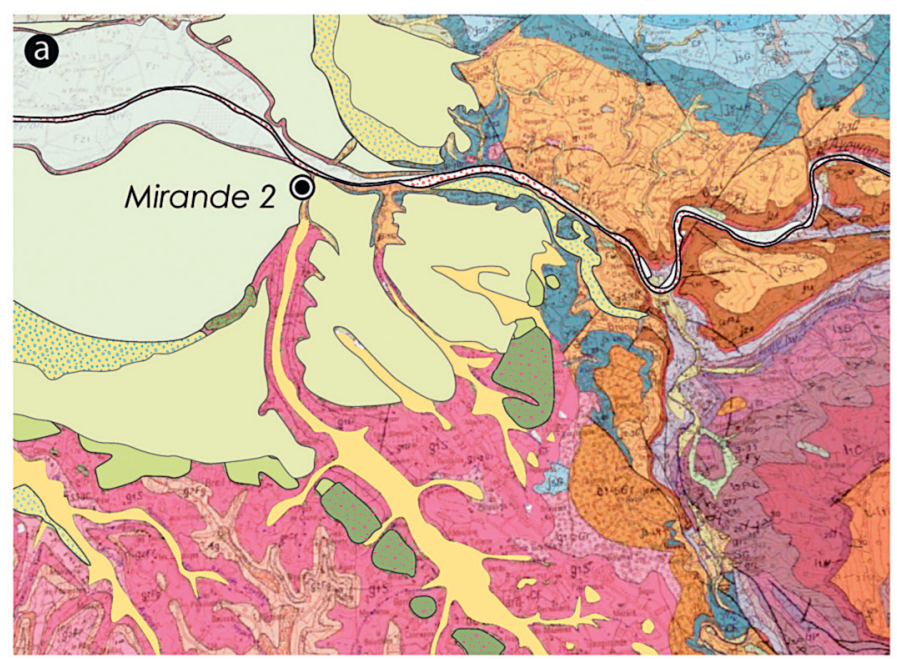

LÉGENDE Formations QuATERnAIRES
Fw. Haute terrasse (Mindel ancien)

Fyl. Basse Terrasse, $2^{\mathrm{e}}$ palier (Riss récent)

Fzl. Basse plaine (Würm récent)

\section{AUtRES FORMATIONS}

Fz2. Alluvions actuelles basse plaine

CF : colluvions et alluvions modernes valles sécondaires (Würm récent à Holocène)
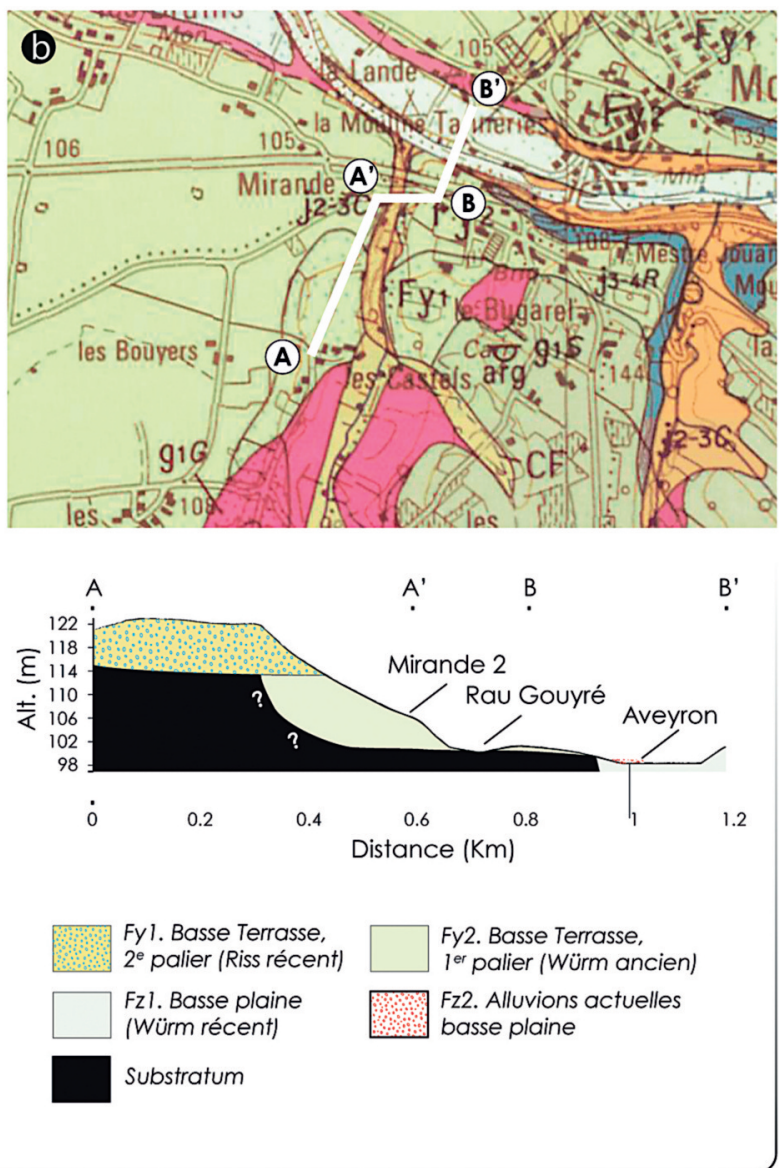

Figure 3 - a : Mirande 2 dans son contexte géologique au sein du système de terrasse de l'Aveyron (carte au 1/50000e, feuille Nègrepelisse ; modifiée d'après Astruc et al., 2000) / $b$ : Coupe géologique simplifiée à l'échelle du site.

Figure 3 - a: The geological context of Mirande 2 within the terrace system of the Aveyron River (scale 1/50000, Nègrepelisse map section; modified after Astruc et al., 2000) / b: Schematic geological section.

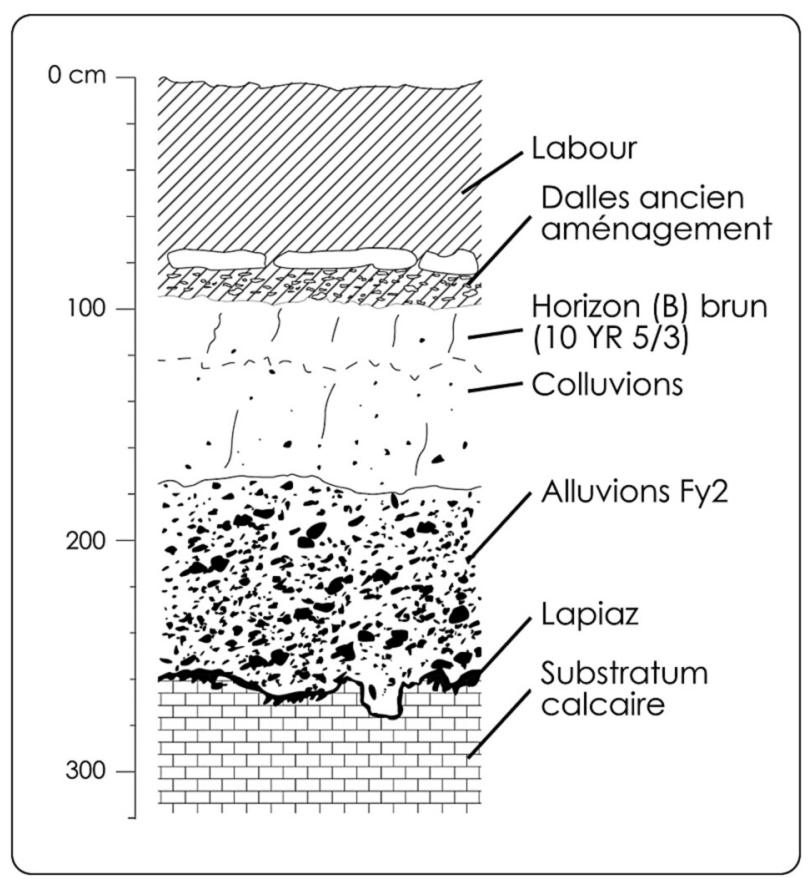

Figure 4 - Coupe synthétique illustrant la succession stratigraphique enregistrée au niveau de la coupe Ouest.

Figure 4 - General stratigraphy of the western section. 

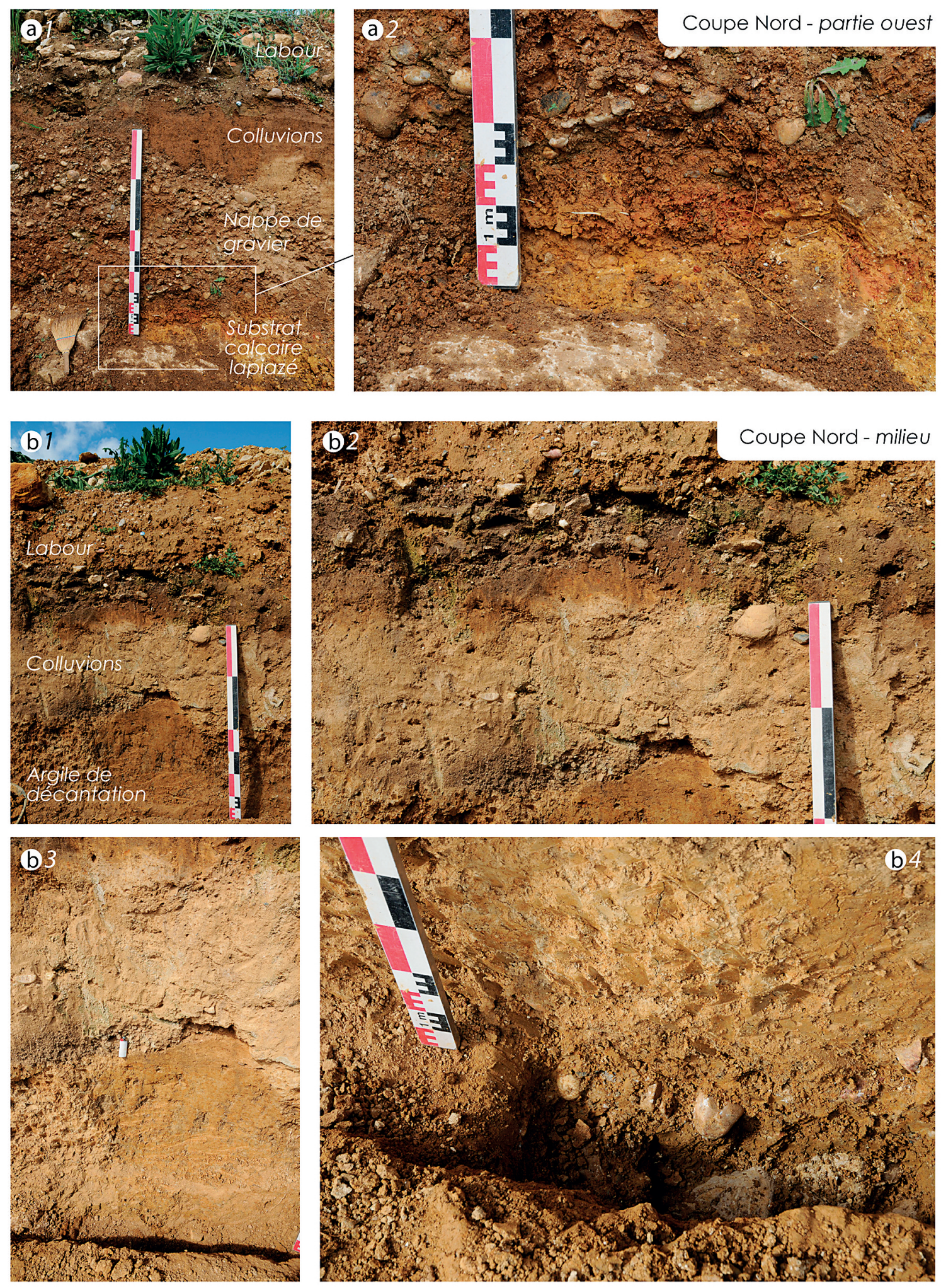

Figure 5 - a, $n^{\circ} 1$ : Séquence stratigraphique de la coupe nord en partie ouest (cf. Log.3 de la figure 6A); $n^{\circ} 2$ : Vue rapprochée montrant la nappe de graviers reposant sur le substratum calcaire lapiazé. Noter la présence du niveau d'argiles d'altération au-dessus du calcaire non altéré / $b, n^{\circ} 1$ : Séquence stratigraphique au milieu de la coupe nord (Log. 6 de la figure $6 A$ ) ; $n^{\circ} 2$ et 3 : Noter en partie basse de la photo le contact érosif entre colluvions et argiles; $n^{\circ} 4$ : Détail de la base de la séquence montrant la nappe de graviers et, au-dessus, les argiles.

Figure 5 - $a, n^{\circ}$ 1: Stratigraphic sequence of the west portion of the northern section (see Log 3 of figure 6A); $n^{\circ} 2:$ Close-up of the gravels resting on the limestone pavement. Note the altered clays overlying the intact limestone / $b, n^{\circ} 1$ : Stratigraphic sequence in the middle of the northern section (see Log 6 of figure $6 A$ ); $n^{\circ} 2$ and 3 : Note the erosion interface between the colluvium and decanted clays at the base of the photo; $n^{\circ} 4$ : Close-up of the base of the sequence with the gravels and overlying decanted clays. 


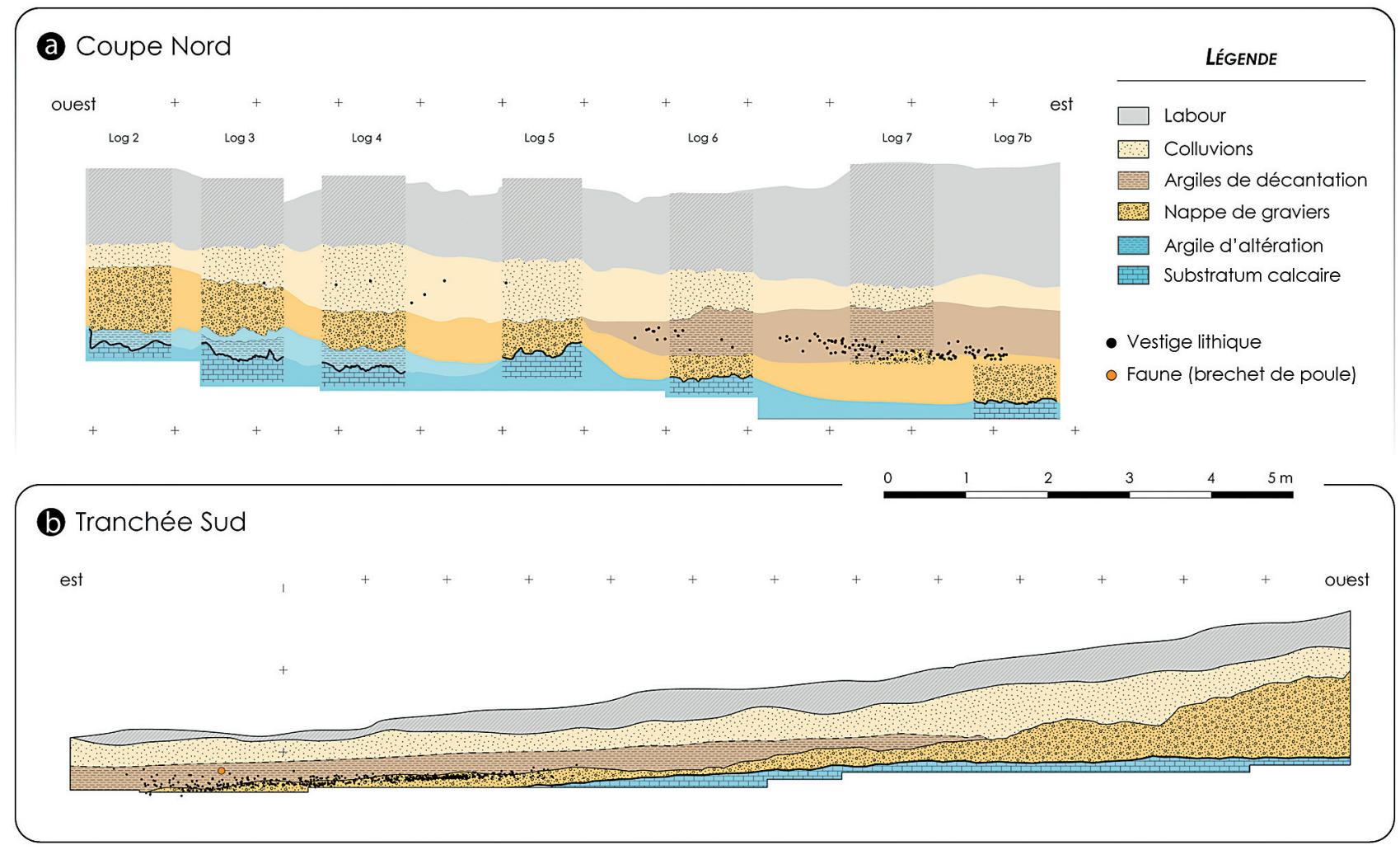

Figure 6 - Relevé synthétique de la stratigraphie des coupes Nord (a) et Sud (b).

Figure 6 - General northern (a) and southern (b) sections.

la forme de lambeaux très localisés. L'élargissement de la vallée de l'Aveyron correspond à la transition entre les calcaires jurassiques et les molasses oligocènes. À l'échelle locale, le site se trouve en partie basse d'un versant à pente douce faisant la jonction entre les terrasses Fy1 et Fy2 (fig. 3b). À environ $50 \mathrm{~m}$ à l'est du site, la terrasse Fy2 est entaillée par le ruisseau du Gouyré, petit affluent de l'Aveyron orienté N-S le long duquel affleurent les calcaires jurassiques de la Formation de Cajarc. Le terrassement du chantier a permis de dégager deux longues coupes orientées E-O et une coupe orientée N-S (fig. 1c). De haut en bas, la succession des dépôts de la Coupe Ouest (N-S) est la suivante (fig. 4) :

- Au sommet $(0-95 \mathrm{~cm})$ : remblais liés à l'aménagement de la parcelle. La partie inférieure $(50-95 \mathrm{~cm})$ est constituée par des dalles de béton correspondant à un aménagement moderne ;

- Entre 95 et $175 \mathrm{~cm}$ : limons argileux brun (10YR 5/3) à brun clair associés à des graviers de petit module. Le sédiment est bioturbé jusqu'à la base de l'unité. Un horizon $B$ de sol brun peu marqué est visible sur les premiers $30 \mathrm{~cm}$ de l'unité. Vers sa base, l'unité s'enrichit en fraction grossière (graviers, gravillons et petits galets). Cette unité est recoupée par un petit réseau de fentes à espacement infra métrique qui se prolongent localement dans l'unité inférieure ;
- Entre 175 et $260 \mathrm{~cm}$ : unité de graviers, gravillons et galets arrondis $(<10 \mathrm{~cm})$ dont le cortège minéralogique est dominé par le quartz, le gneiss et différents types de granites. Le support est clastique et la matrice limonoargileuse. Le contact avec l'unité sous-jacente est érosif ; - Enfin, entre 260 et $320 \mathrm{~cm}$ : substrat calcaire lapiazé marqué par une mince couche d'argiles d'altération à l'interface entre l'unité de graviers et le calcaire non altéré.

L'unité au contact avec le substratum calcaire résulte de la mise en place de la terrasse Fy2 de l'Aveyron (fig. 3b). En revanche, le faciès diamictique de l'unité sus-jacente suggère une mise en place par colluvionnement des formations situées en amont du site (terrasse Fy1). Dans leur moitié ouest, les coupes orientées E-O montrent la même succession stratigraphique que la coupe précédemment décrite (exemple de la coupe Nord : fig. 5a). Plus à l'est, une unité supplémentaire apparaît entre les colluvions et le sommet de l'unité graveleuse (fig. 5b). Ce sont des argiles limoneuses à structure polyédrique arrondie, à rares gravillons. La présence de gravillons est probablement le résultat de la migration de petits graviers le long du réseau de fissures associées avec le sol brun ou de la dispersion de petits graviers provenant de la nappe de graviers sous-jacente liés aux cycles de retrait/gonflement des argiles (e.g. Poesen et Lavee 1994; Moeyerson et al. 


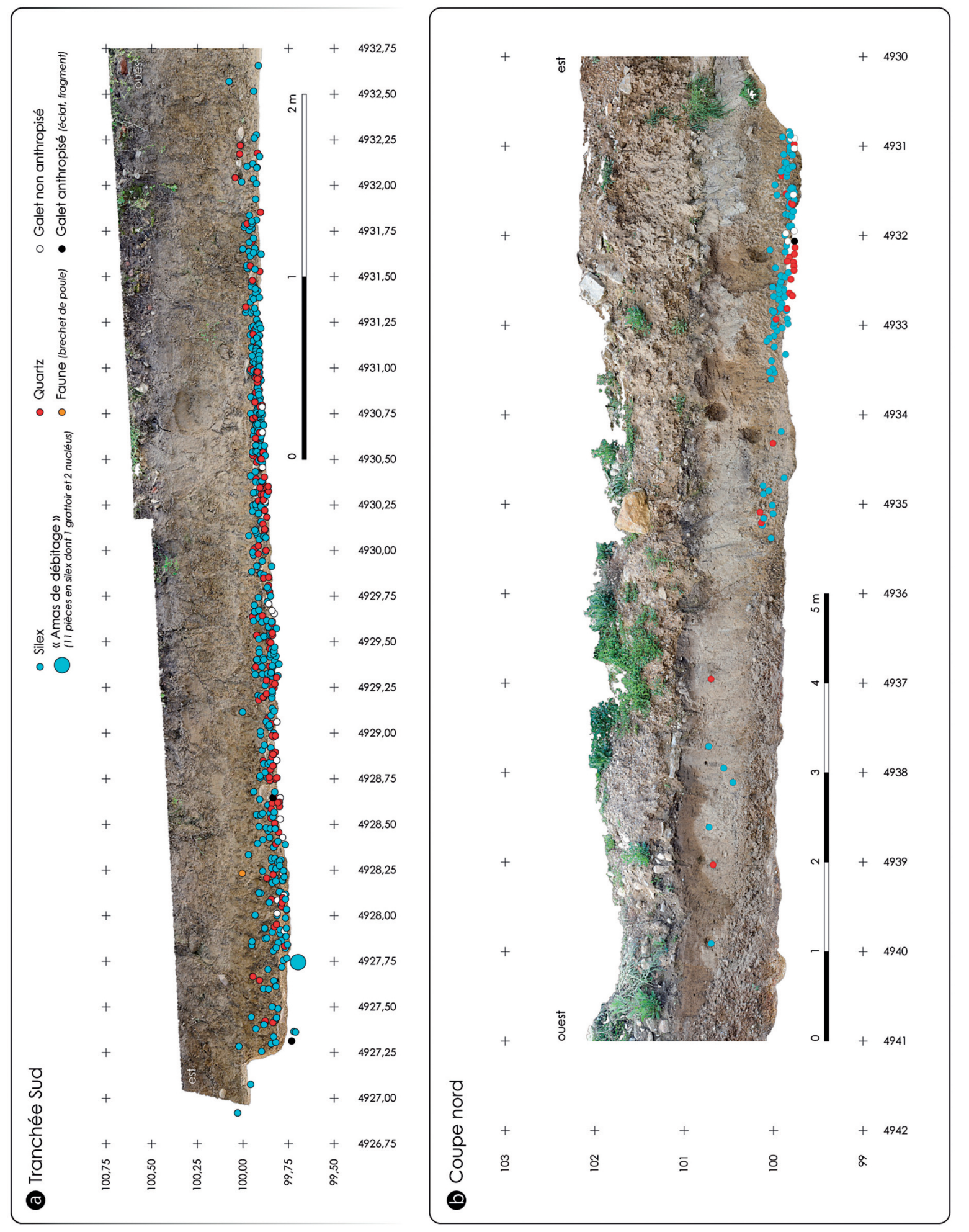

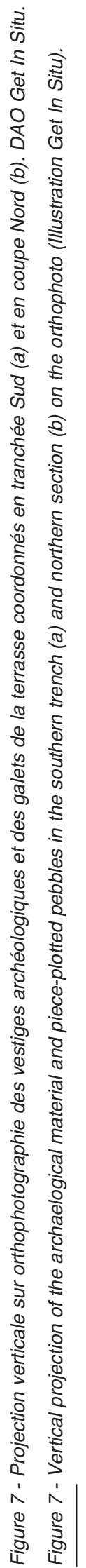




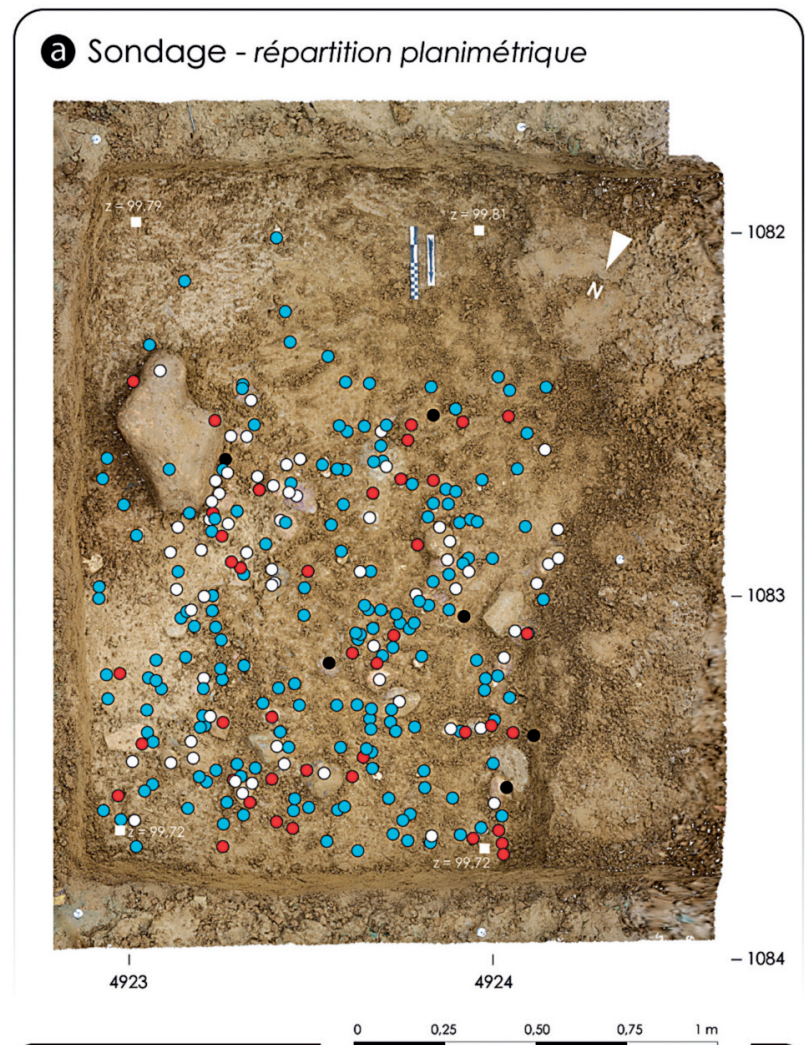

b Sondage - projection verticale

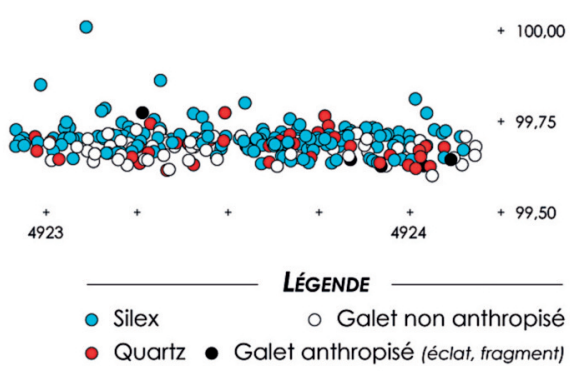

Figure 8 - Sondage : projection en plan sur orthophotographie (a) et projection verticale (b) des vestiges archéologiques et des galets de la terrasse coordonnés. DAO Get In Situ.

Figure 8 - Test-pit: horizontal (a) and vertical (b) projections of archaeological material and piece-plotted terrace pebbles on the orthophoto (Illustration Get In Situ).

2006). Globalement, le litage au sein de cette unité n'est pas préservé en raison de la bioturbation associée au sol brun actuel, mais localement nous avons pu observer des lits argileux d'épaisseur millimétrique préservés. L'unité est tronquée à son sommet par les colluvions.

\subsection{1 - Géométrie des dépôts et localisation stratigraphique des vestiges anthropiques}

La reconstitution de la géométrie des dépôts sur les coupes nord et sud a été réalisée à partir de logs stratigraphiques et d'observations de terrain (fig. 6). L'unité graveleuse repose toujours sur le substratum calcaire lapiazé et son épaisseur diminue rapidement d'ouest en est. Des argiles apparaissent à partir de la moitié des deux coupes et s'épaississent progressivement vers l'est. L'épaisseur des colluvions de versant diminue d'ouest en est (fig. 6b). Elles recoupent d'abord le sommet de l'unité graveleuse (moitié ouest) et ensuite le sommet de l'unité argileuse. Si dans la partie ouest de la coupe Sud quelques vestiges dispersés ont été récoltés dans les colluvions (notamment associés à des éléments intrusifs modernes : restes de poule domestique et de rat), les vestiges archéologiques sont situés au sommet de la nappe de galets.

\subsection{2 - Un niveau unique géologiquement in situ}

Les projections verticales réalisées en aval de la fouille (fig.7 et 8) et la projection des vestiges sur la coupe géologique (fig.6) montrent que la majorité des vestiges est dispersée sur une épaisseur de $20 \mathrm{~cm}$. Dans la figure 9, on voit clairement que le nombre de vestiges par décapage suit une distribution normale, critère retenu pour appuyer l'hypothèse d'un niveau archéologique unique (e.g. Delagnes et al. 2006). Toutefois, cette hypothèse devra être précisée par un test systématique des remontages lithiques. Les quelques tests de tamisage à l'eau effectués sur le terrain et en laboratoire (colonne-test, prélèvement " en masse » : voir supra) ont confirmé la présence, tout du moins dans les secteurs testés, de microvestiges au sein du niveau, matérialisés par des esquilles et/ou microdébris $(<5 \mathrm{~mm}$ ) de silex et de quartz (fig. 9 et tabl. 1). Les microcharbons associés aux vestiges lithiques doivent être considérés avec prudence puisque certains d'entre eux, soumis à datations ${ }^{14} \mathrm{C}$ dans le cadre du PCR SaM (Ducasse et Renard coord. 2017), ont livré une mesure aberrante (OxA 33217 : $300 \pm 25$ BP). En conclusion, même si à l'heure actuelle le degré de préservation du site ne peut pas être estimé, on peut au moins en conclure qu'il est géologiquement in situ, c'est à dire qu'il a le même âge que les dépôts dans lequel il est contenu.

\section{2 - Les équipements techniques : vue synthétique}

Compte tenu des conditions de l'intervention de terrain et des contraintes y afférant, précisons avant toute chose que l'assemblage récolté correspond à un corpus d'étude biaisé par la représentativité spatiale de la fenêtre exploitée (trois locus disjoints pour un total de $15 \mathrm{~m}^{2}$ fouillés, soit moins de $1 \%$ de la surface minimale estimée à environ 0,2 ha), mais également par la diversité des approches appliquées selon les secteurs (i.e. ravivages de coupes, fouille planimétrique ; tamisage non systématique : voir supra). Les vestiges archéologiques étudiés, composés exclusivement de restes lithiques, sont au nombre de 891 et sont répartis en 675 pièces en silex (tabl. 2 et 3 ), 212 éléments de quartz (tabl. 5) et quatre artefacts réalisés en autres roches. Malgré la disjonction des secteurs fouillés et les biais relatifs à la constitution des différents lots, l'analyse a montré une homogénéité des caractéristiques pétrographiques et technotypologiques de cet assemblage. 


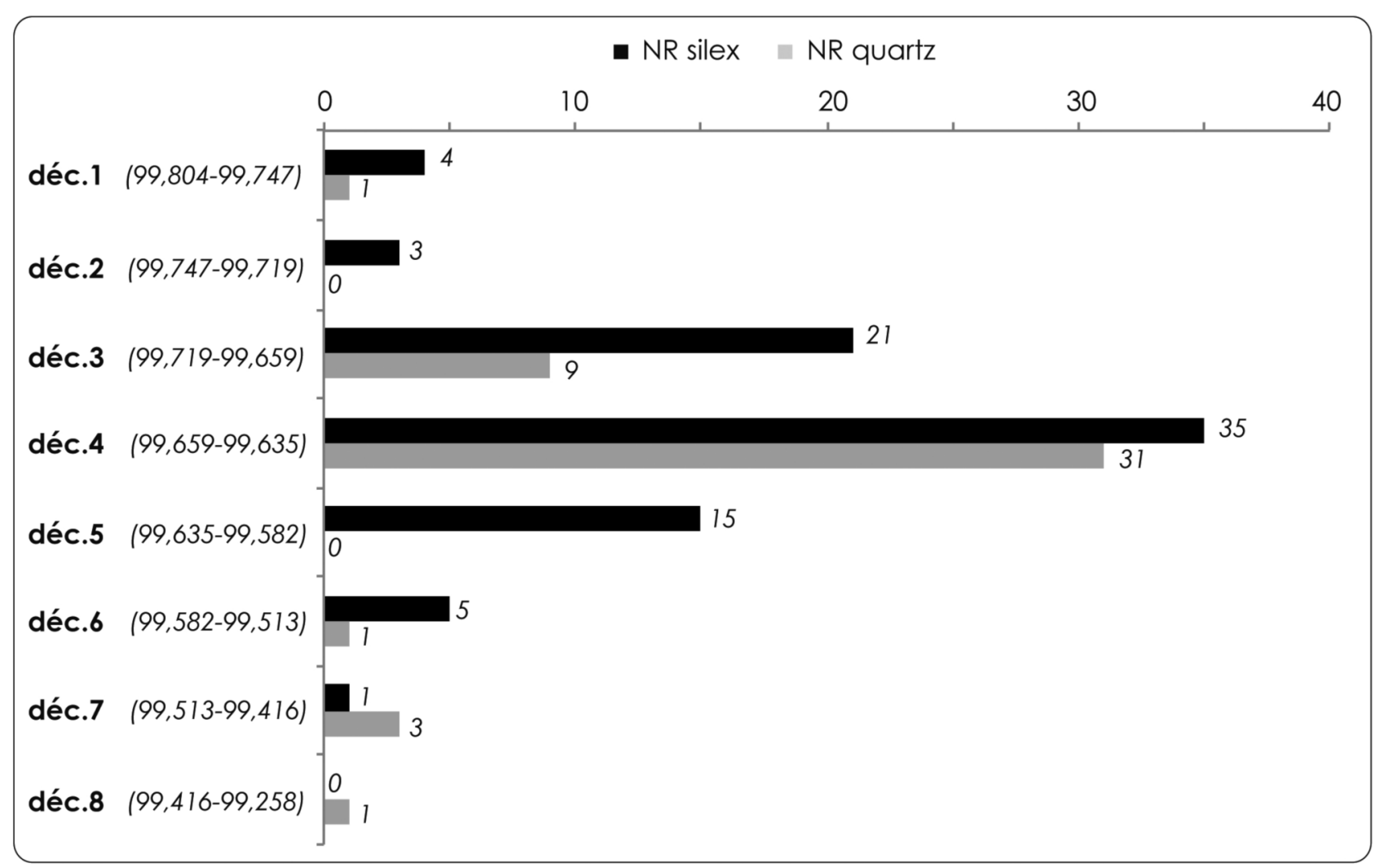

Figure 9 - Sondage, “ colonne test » : décompte des vestiges en silex et en quartz par décapage.

Figure 9 - "Test column" of the test-pit: counts of flint and quartz artefacts by spit.

\begin{tabular}{|c|c|c|c|c|c|c|c|}
\hline SILEX & esquille & ELL & II & éclat & fgt & & NR \\
\hline dec1 & 1 & 2 & 1 & & & & 4 \\
\hline dec2 & 1 & 1 & 1 & & & & 3 \\
\hline dec3 & 12 & 2 & 2 & 2 & & 3 & 21 \\
\hline $\operatorname{dec} 4$ & 15 & 9 & 4 & 7 & & & 35 \\
\hline $\operatorname{dec} 5$ & 9 & 6 & & & & & 15 \\
\hline $\operatorname{dec} 6$ & 5 & & & & & & 5 \\
\hline dec7 & 1 & & & & & & 1 \\
\hline $\operatorname{dec} 8$ & & & & & & & 0 \\
\hline Total & 44 & 14 & 8 & 6 & & 2 & 84 \\
\hline
\end{tabular}

\begin{tabular}{|c|c|c|c|c|c|c|}
\hline QUARTZ & microdébris & débris & éclat & fgt & fgt galet & NR \\
\hline dec1 & & 1 & & & & 1 \\
\hline dec2 & & & & & & 0 \\
\hline dec3 & 6 & & 1 & 2 & & 9 \\
\hline $\operatorname{dec} 4$ & 21 & 7 & 2 & & 1 & 31 \\
\hline dec5 & & & & & & 0 \\
\hline $\operatorname{dec} 6$ & 1 & & & & & 1 \\
\hline $\operatorname{dec} 7$ & 2 & 1 & & & & 3 \\
\hline dec 8 & 1 & & & & & 1 \\
\hline Total & 31 & 9 & 3 & 2 & 1 & 46 \\
\hline
\end{tabular}

Tableau 1 - Sondage, «colonne test » : décompte des vestiges par décapages selon le matériau et les types de supports.

Table 1- Flint and quartz blanks from the test column of the testpit by spit.

\begin{tabular}{|c|c|c|c|}
\hline Matière première & Nombre & $\%$ det & $\%$ total \\
\hline Tertiaire & 531 & 88,8 & 78,7 \\
\hline dont type Verdier & 63 & & \\
\hline Silex Jaspéroïdes & 33 & 5,5 & 0,8 \\
\hline dont jurassique & 1 & & \\
\hline dont tertiaire & 21 & & \\
\hline Sénonien & 20 & 3,3 & 3,0 \\
\hline dont blond & 4 & & \\
\hline Fumélois & 8 & 1,3 & 1,2 \\
\hline Bergeracois & 3 & 0,5 & 0,4 \\
\hline Silex à Lepidorbitoides sp. & 3 & 0,5 & 0,4 \\
\hline sous-total dét. & 598 & 100,0 & 84,5 \\
\hline Indét & 55 & & 8,1 \\
\hline Indét allochtone & 22 & & 3,3 \\
\hline dont possible Flysch & 5 & & \\
\hline sous-total indét. & 77 & & \\
\hline TOTAL & 675 & & \\
\hline
\end{tabular}

Tableau 2 - Composition lithologique de l'assemblage en silex (cumul des trois secteurs; hors ramassages de surface, refus de tamis et " colonne test ").

Table 2 - Siliceous raw materials (from three sectors excepted surface collecting, sieve residus and Test-pit). 
TER JASP $\begin{gathered}\text { JASP } \\ \text { tertiaire }\end{gathered} \underset{\text { jurassique }}{\text { JASP }}$ SENO FUM BGC CHA Ind. Ind. ALL TOTAL

\begin{tabular}{|c|c|c|c|c|c|c|c|c|c|c|c|}
\hline \multicolumn{12}{|l|}{ Produits/sous-produits bruts } \\
\hline éclat & 155 & 5 & 5 & & 3 & 2 & 1 & & 16 & 2 & 189 \\
\hline dont mince & 4 & & & & & & & & & & 4 \\
\hline dont cortical & 29 & & & & & & & & 2 & & 31 \\
\hline dont semi-cortical & 12 & & & & & & & & 1 & & 13 \\
\hline éclat laminaire & 55 & & 1 & & 3 & & & & 4 & 2 & 65 \\
\hline dont cortical & 2 & & & & & & & & & & 2 \\
\hline dont semi-cortical & 17 & & 1 & & 1 & & & & 2 & & 21 \\
\hline éclat lamellaire & 80 & 3 & 1 & & 5 & 1 & & & 8 & 2 & 100 \\
\hline dont cortical & 1 & & & & & & & & & & 1 \\
\hline dont semi-cortical & 8 & & & & & & & & & & 8 \\
\hline Lame & 2 & 1 & 1 & & 3 & & & & & 1 & 8 \\
\hline dont semi-cortical & & & & & 1 & & & & & & 1 \\
\hline Lamelle & 52 & 1 & 3 & & 2 & 1 & & & 5 & 2 & 66 \\
\hline dont semi-cortical & 2 & & & & & & & & 1 & & 3 \\
\hline fragment indét. & 129 & & 6 & & 1 & & & & 14 & 6 & 156 \\
\hline esquille & 18 & 1 & & & & & & & 2 & 1 & 22 \\
\hline indéterminé & 2 & & & & & 1 & & & & & 3 \\
\hline nucléus & 21 & & 3 & & & 2 & & & 1 & 1 & 28 \\
\hline dont à éclats & 5 & & & & & & & & & & 5 \\
\hline dont à éclats laminaires & 1 & & & & & & & & & & 1 \\
\hline dont à lamelles & 14 & & 2 & & & 1 & & & 1 & 1 & 19 \\
\hline rognon & 2 & & & & & & & & & & 2 \\
\hline sous-total & 516 & 11 & 20 & & 17 & 7 & 1 & 0 & 50 & 17 & 639 \\
\hline Equipement retouché & & & & & & & & & & & \\
\hline Outillage de transformation & 12 & & 1 & 1 & 3 & & 2 & 2 & 2 & 5 & 28 \\
\hline Armatures & 3 & & & & & 1 & & 1 & 3 & & 8 \\
\hline sous-total & 15 & & 1 & 1 & 3 & 1 & 2 & 3 & 5 & 5 & 36 \\
\hline
\end{tabular}

Tableau 3 - Décompte techno-typologique de l'assemblage en silex en fonction des différentes matières premières exploitées (cumul des trois secteurs; hors ramassages de surface, refus de tamis et « colonne test »; TER : Tertiaire, JASP : Jaspéroïde, SENO : Sénonien, FUM : Fumélois, BGC : Bergeracois ; CHA : silex à Lepidorbitoides sp., Ind. ALL : indéterminé allochtone).

Table 3 - Technological \& typological counts of flints by raw material (from three sectors excepted surface collecting, sieve residus and Test-pit).

La nature des industries mises au jour est tout à fait compatible avec une attribution au Badegoulien.

\subsection{1 - Les industries en silex}

\section{Origine et économie des matières premières}

L'intégralité des quartz et des autres roches est d'origine vraisemblablement locale (voir infra). L'analyse de la provenance des silex exploités à Mirande 2, basée sur la diagnose du fonds micropaléontologique et de la structure sédimentaire des pièces (loupe binoculaire ; x 7,5 à x 50), indique une grande diversité géographique des lieux d'approvisionnement (fig. 10a). Au sein du corpus étudié, l'origine de près de $85 \%(\mathrm{~N}=598)$ des silex a pu être déterminée et plusieurs types identifiés (tabl. 2):

- Les silex tertiaires sont généralement caractérisés par la présence de characées et oogones (fig. 10b $n^{\circ} 1$ ) ou de gastéropodes continentaux, notamment de type Lymnae (Morala 1980 ; Mouline 1983 ; Chalard et al. 1996 ; Turq 2000 ; Turq et Morala 2013). Bien qu'une part d'entre eux, montrant des plages corticales pas ou peu érodées, pourrait bien provenir des affleurements du Verdier situés à une vingtaine de $\mathrm{km}$ au sud-est du site (fig. $\left.10 \mathrm{~b} \mathrm{n}{ }^{\circ} 2\right)^{5}$, la forte fréquence de cortex alluviaux permet de supposer un approvisionnement plus strictement local, sur les plages de la Vère ou de l'Aveyron.

- Les silex jaspéroïdes forment un groupe hétérogène auquel il reste généralement difficile d'assigner une origine géologique et géographique précise, faute de caractéristiques structurales ou de marqueurs micropaléontologiques spécifiques. Parmi eux, les silex jaspéroïdes d'âge tertiaire se caractérisent par un aspect gras et luisant ainsi que par la présence de characées, sans pour autant que leur provenance exacte puisse être déterminée. Signalons au demeurant l'existence d'au

(5) Les distances gîtes/sites exprimées correspondent à des distances orthodromiques. Ces valeurs restent indicatives et ne tiennent donc pas compte de la diversité potentielle des modes d'acquisitions et de circulation de ces matériaux. 


\begin{tabular}{|c|c|c|c|c|c|c|}
\hline Outillage de transformation & lame & EL lamelle & éclat & fgt indét & indét & TOTAL \\
\hline Grattoir & 2 & 1 & & & & 3 \\
\hline Grattoir sur lame retouchée & 1 & & & & & 1 \\
\hline Grattoir-bec & & 1 & 1 & & & 2 \\
\hline Burin sur troncature & & & & 1 & & 1 \\
\hline Perçoir/bec & & 1 & & & & 1 \\
\hline Encoche & & & 1 & & & 1 \\
\hline Troncature & & 1 & & & & 1 \\
\hline Lame retouchée & 2 & & & & & 2 \\
\hline Pièce esquillée & & 1 & 1 & 1 & & 3 \\
\hline Raclette & & & 8 & & & 8 \\
\hline Racloir & & & 1 & & & 1 \\
\hline $\begin{array}{l}\text { Pièces à retouches et } \\
\text { ébréchures lat. }\end{array}$ & & & 2 & 1 & 1 & 4 \\
\hline
\end{tabular}

\section{Equipement cynégétique}

\begin{tabular}{lll}
\hline Lamelle à dos simple & 3 & 3 \\
Lamelle à dos et ret. opp & 2 & 2 \\
Pointe à dos et ret. opp & 1 & 1 \\
Microlamelle à dos appointée & 1 & 1 \\
Ebauche de lamelle à dos & 1 & 1 \\
\hline \multicolumn{1}{c}{ Sous-total } & 8 & 8 \\
\cline { 2 - 3 } & & TOTAL 36 \\
\cline { 2 - 3 }
\end{tabular}

Tableau 4 - Outillage et armatures versus types de supports (EL : éclat laminaire, fgt : fragment).

Table 4 - Tools and Microliths blanks.

\begin{tabular}{|c|c|c|c|c|c|c|c|}
\hline & Débitage & polaire s & enclume & Percussion lancée & Modalité de & Percuteur & TOTAL \\
\hline & certain & probable & possible & & fracturation indéterminée & & IVIAL \\
\hline éclat & 41 & 5 & & 3 & 15 & & 64 \\
\hline dont cortical & 19 & & & & 2 & & 21 \\
\hline dont semi-cortical & 14 & 3 & & & 1 & & 18 \\
\hline micro-éclat & & & & & 2 & & 2 \\
\hline fragments & 16 & 1 & 3 & & 24 & & 44 \\
\hline dont cortical & 4 & & 1 & & 7 & & 12 \\
\hline dont semi-cortical & 1 & & & & & & 1 \\
\hline débris & & & & & 49 & & 49 \\
\hline micro-débris & & & & & 10 & & 10 \\
\hline galet et frag. de galets & 7 & 1 & 1 & & 8 & 1 & 18 \\
\hline nucléus et frag. de nucléus & 18 & & & 1 & 1 & & 20 \\
\hline dont recyclage percuteur & 1 & & & & & & 1 \\
\hline indéterminé & & & & & 4 & & 4 \\
\hline racloir & & & & & 1 & & 1 \\
\hline TOTAL & 82 & 7 & 4 & 4 & 114 & 1 & 212 \\
\hline
\end{tabular}

Tableau 5 - Composition techno-typologique de l'assemblage en quartz (cumul des trois secteurs; hors ramassages de surface, refus de tamis et « colonne test »).

Table 5 - Technological \& typological counts of quartz (from three sectors excepted surface collecting, sieve residus and Test-pit). 

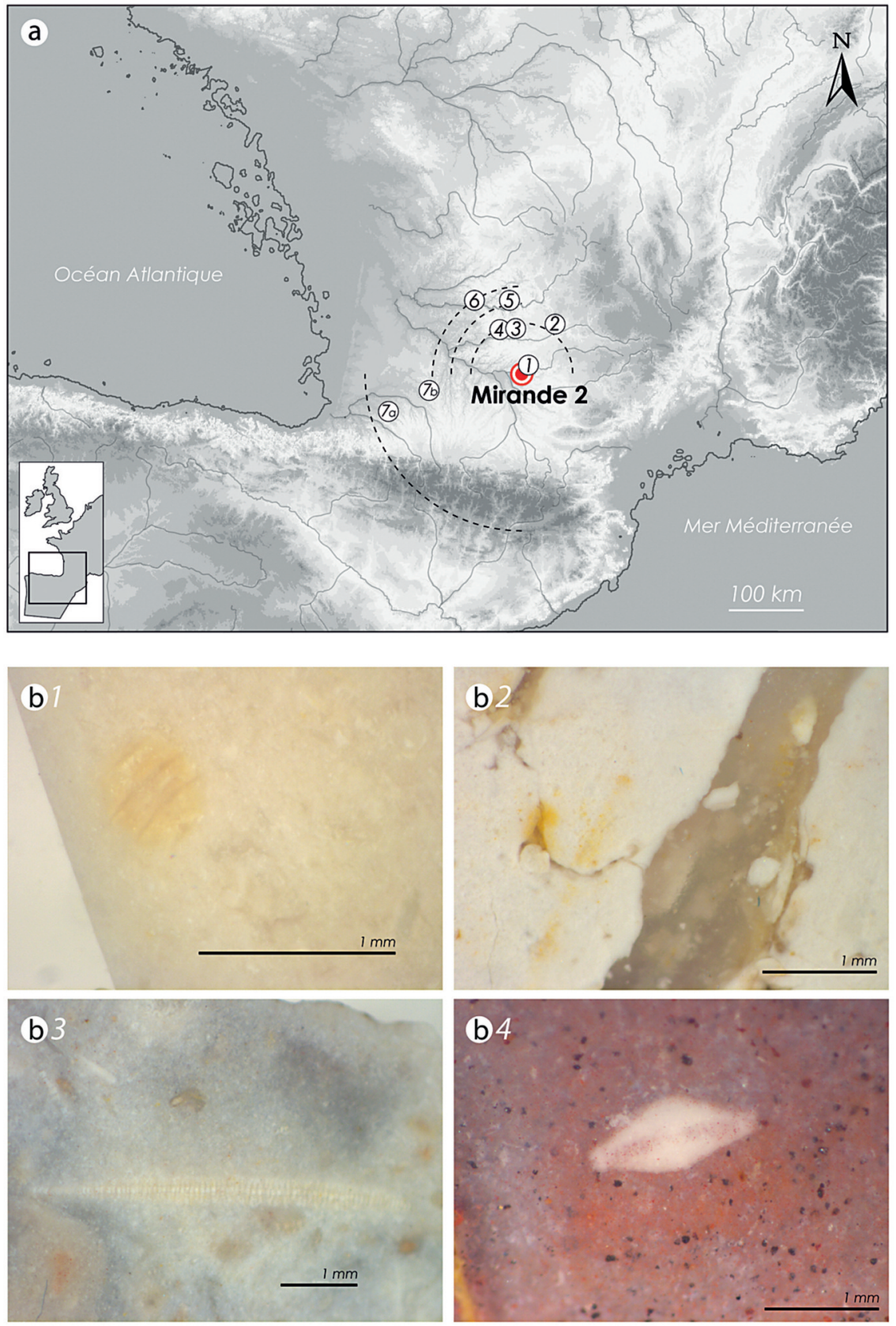

Figure 10 - a : Carte de provenance des types de silex rencontrés à Mirande 2 (cercles de distances : $200 \mathrm{~km}, 120 \mathrm{~km}$, $90 \mathrm{~km}$ et $65 \mathrm{~km}) ; n^{\circ} 1$ : Tertiaire, $n^{\circ} 2$ : Jurassique, $n^{\circ} 3$ : Sénonien blond, $n^{\circ} 4$ : Fumélois,

$n^{\circ} 5$ : Sénonien gris-noir, $n^{\circ} 6$ : Bergeracois,

$n^{\circ} 7 a$ et $b$ : Silex à

Lepidorbitoïdes sp.) /

$b$ : Exemples d'éléments micropaléontologiques et/ou de structures internes

caractéristiques, $n^{\circ} 1$ : exemple d'oogones, silex tertiaire ; $n^{\circ} 2$ : structure typique des silex du Verdier; $n^{\circ} 3$ : Lepidorbitoïdes sp., silex de Chalosse sensu lato ; $n^{\circ} 4$ : Orbitoïdes Media, silex du Bergeracois, clichés $G$. $C$.

Figure 10 - a: Provenience of different siliceous raw materials documented at Mirande 2 (distance radii : $200 \mathrm{~km}, 120 \mathrm{~km}$, $90 \mathrm{~km}$ and $65 \mathrm{~km}$ ); $n^{\circ}$ 1: Tertiary, $n^{\circ} 2$ : Jurassic, $n^{\circ} 3$ : Blond Senonian, $n^{\circ}$ 4: Fumelois, $n^{\circ}$ 5: Black-grey Senonian, $n^{\circ}$ 6: Bergeracois,

$n^{\circ} 7 a$ and b: Flint with Lepidorbitoides sp. /

b: Micropalaeontological and or characteristic internal structures, $n^{\circ}$ 1: example of an oogonium, Tertiary flint; $n^{\circ} 2$ : typical structure of Verdier flint; $n^{\circ}$ 3: Lepidorbitoides sp., Challosse flint sensu lato; $n^{\circ}$ 4: Orbitoides media, Bergeracois flint. moins une pièce présentant une structure oolithique et rapportable aux formations jurassiques connues en bordure du Massif central, c'est-à-dire à au moins $60 \mathrm{~km}$ au nord-est du gisement (fig. 10a $\mathrm{n}^{\circ} 2$; Séronie-Vivien 1987 ; Turq et Morala 2013).

- Les silex du Sénonien sensu lato, qu'il s'agisse des variétés gris-noires ou blondes, sont disponibles dans un même secteur compris dans un rayon de 65 à $100 \mathrm{~km}$ au nord du site (fig. 10a nos 3 et 5 ; Turq 2000 ; Fernandès 2012 ; Turq et Morala 2013).
- Les silex du Fumélois issus des formations du Turonien inférieur localisées près de Fumel (Morala, 1980 ; Turq et Morala, 2013), sont disponibles à au moins $65 \mathrm{~km}$ au nord du gisement (fig. 10a $n^{\circ} 4$ ).

- Trois pièces signent sans ambiguïté l'apport de silex du Bergeracois (fig. 10b $\mathrm{n}^{\circ} 4$ ), matérialisant un déplacement de matière sur près de $120 \mathrm{~km}$ depuis le nord du site (fig. 10a $n^{\circ} 6$ ).

- La présence de silex à Lepidorbitoïdes sp. (fig. 10b n 3 ) parfois associés à des sidérolithes $\mathrm{sp}$. et sans orbitoïdes 
media témoigne de l'exploitation de matériaux dont les gîtes se situent soit en Chalosse (fig. 10a $n^{\circ} 7 \mathrm{a}$; Bon et al. 2002 ; Séronie-Vivien et al. 2006 ; Chalard et al. 2010), soit dans le Gers (fig. 10a $n^{\circ} 7 \mathrm{~b}$; Colonge et al., 2011). En l'état des connaissances, les gîtes primaires ou sub-primaires se situent à plus de $120 \mathrm{~km}$ à vol d'oiseau au sud-ouest du gisement.

À ces différents types, et en dehors des silex indéterminés stricto sensu ( $\mathrm{N}=55$, soit environ $8 \%$ de l'ensemble), s'ajoute un certain nombre de pièces issues de formations marines mais dépourvues des caractères permettant une attribution pétrographique et géographique précise. Dans la mesure où leur structure se rapproche souvent de celle observée pour les silex du Sénonien et ne trouve aucun équivalent au sein des matériaux disponibles localement ou régionalement, nous avons pris le parti de considérer ces divers éléments comme des matériaux allochtones d'origine indéterminée (tabl. 2). Enfin, plusieurs pièces offrent des caractéristiques proches des silex du Flysch pyrénéen $(\mathrm{N}=5)$. Si cette attribution était confirmée, l'importation de ce matériau nécessitait de parcourir plus de 200 km entre les gîtes et le site de Mirande 2.

En tenant compte de la nature des pièces et de la forme sous laquelle ces différents éléments ont été introduits sur le gisement (i.e. fragmentation des chaînes opératoires), trois cas de figure ont pu être distingués : 1) des silex tertiaires locaux qui témoignent d'une mise en œuvre in situ des différentes productions identifiées (éclats, lames et lamelles) ; 2) des matériaux allochtones introduits sous la forme d'outils et de volumes à débiter des lamelles (silex du Bergeracois et du Fumélois) ; 3) des silex allochtones documentés uniquement sous la forme d'outils ou de supports bruts " prêts à l'emploi » (silex à Lepidorbitoides $s p$. et Flysch possible : fig. $11 \mathrm{n}^{\circ} 1$ ).

\section{Nature des équipements et caractères technologiques}

L'équipement retouché comprend 36 éléments répartis en 28 outils à vocation domestique réalisés tant à partir de produits et sous-produits des productions laminaires ( $\mathrm{N}=10$ lames et éclats laminaires) que d'éclats issus de débitages essentiellement autonomes ( $\mathrm{N}=14$ éclats), ainsi que 8 microlithes, éléments d'armatures lamellaires potentiels (tabl. 4).

Marqué par les grattoirs (fig. $11 \mathrm{n}^{\text {os }} 1,4,5$ et 8 ), souvent importés et parfois associés à d'autres parties actives $\left(n^{\circ} 6\right)$, l'outillage de transformation se singularise par la présence de plusieurs raclettes ( $\mathrm{N}=8$ : fig. $12 \mathrm{n}^{\circ \mathrm{s}} 1$ à 7$)$. Découvertes dans l'ensemble des secteurs fouillés, ces pièces répondent sans écart notable aux « canons 》 badegouliens. Si l'emploi d'éclats minces renvoie à la mise en place d'une production dédiée et autonome, largement décrite par ailleurs (e.g. Bracco et al. 2003 ; fig. 12 n 9), une pièce documente la sélection conjointe mais discrète de supports laminaires $\left(n^{\circ} 5\right)$. En dehors des exemplaires produits in situ à partir des ressources locales (nos 1 et 3 ), cette catégorie d'outils se distingue comme celle des grattoirs par l'usage de matériaux allochtones, sans qu'il soit possible, au regard des biais constitutifs de la série, de démontrer définitivement le caractère différé de leur production ( $\mathrm{n}^{\text {os }} 2,6$ et 7 ). En dehors des lames retouchées $(\mathrm{N}=2)$, d'un unique racloir (fig. $\left.13 \mathrm{n}^{\circ} 2\right)$ et des pièces à retouches et ébréchures latérales ( $\mathrm{N}=4$; cf. couteaux), quelques pièces esquillées complètent l'inventaire des principaux outils récoltés à Mirande 2 (fig. $13 n^{\text {os }} 1$ et 3 ). Notons que certains indices laissent suggérer la mise en place d'un débitage bipolaire sur enclume (fig. $15 n^{\circ} 1$ ?), méthode de production faisant partie du bagage technique des groupes badegouliens ; en témoignent à l'échelle du site les modalités d'exploitation du quartz (voir infra) mais aussi, à une échelle plus large, l'examen de gisements « classiques » quercinois et aquitains (Le Cuzoul de Vers : Ducasse 2010 ; Cassegros : Ducasse et Le Tensorer dir. 2016).

En l'état de l'analyse et malgré l'absence de nucléus, l'examen des quelques produits laminaires intégrés ou non à l'équipement $(\mathrm{N}=13)$ permet de proposer deux schémas opératoires de production liés à la recherche de supports aux caractéristiques morphométriques distinctes : (1) une production laminaire cintrée générant des produits plutôt étroits (p.e. fig. $11 \mathrm{n}^{\text {os }} 3$ et 4 ), accompagnée (2) d'un débitage de supports plats et envahissants sur face large (p. e. fig. $11 \mathrm{n}^{\circ}$ 1). La mise en œuvre, au Badegoulien, d'un schéma opératoire de production de lames et produits allongés à partir de surfaces planes a déjà été signalée (e.g. Parrain Nord, Dordogne : Fourloubey 1998 ; Oisy, Nièvre : Bodu, Chehmana, Debout 2007 ; Seyresse, Landes : Ducasse 2010). Sa relation avec certaines productions faciales d'éclats minces de grand gabarit méritera d'être discutée (fig. $11 \mathrm{n}^{\circ} 2$ ?), à Mirande comme ailleurs, à partir d'un corpus plus conséquent et le concours de remontages physiques. Enfin, notons que les matériaux locaux sont également exploités dans le cadre d'une production à la pierre d'éclats laminaires (voire de lames) selon des modalités relativement souples qui permettent aux tailleurs de tirer profit de galets aux dimensions et morphologies propices (phase de conformation des volumes quasi-inexistante, mise à profit des convexités naturelles, exploitation sur faces étroites).

Le registre cynégétique est, quant à lui, essentiellement documenté à travers la présence de microlithes $(\mathrm{N}=8$ : fig. $14 \mathrm{n}^{\circ \mathrm{s}} 1$ à 7 ) et de produits et sous-produits liés à l'obtention de leurs supports, exclusivement lamellaires (tabl. 3 et 5 et fig. 15). Si la plus grande part de ces éléments correspond à l'exploitation des matériaux locaux, d'autres pièces témoignent de l'emploi de silex allochtones (notamment silex sénoniens et du Fumélois), suggérant l'import (encore emmanchés ?) de produits finis ou de volumes à débiter (nucléus et/ou sous-produits). En dehors d'un fragment d'ébauche en silex à Lepidorbitoïdes sp., les microlithes de Mirande 2 regroupent des lamelles à dos simples et envahissants (fig. 14, nos 2,5 et 6), des lamelles à dos envahissants et retouche opposée du tranchant (fig. 14, nos 3 et 4) - dont l'une peut être considérée comme une pointe au regard de la convergence proximale de ses bords $\left(n^{\circ} 1\right)$ - et une microlamelle à dos effilée $\left(n^{\circ} 7\right)$. Bien qu'elles proviennent des différents tests de tamisage 

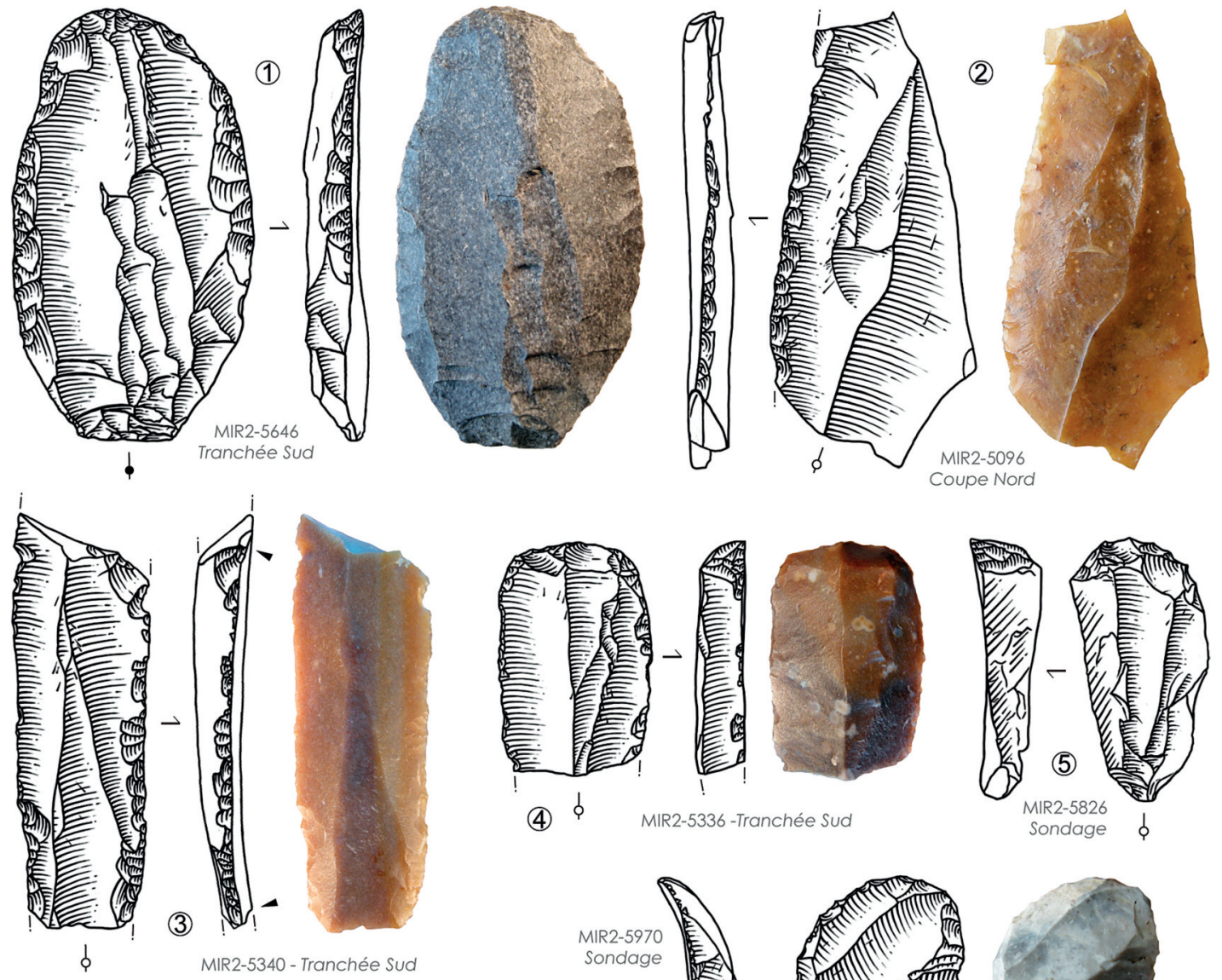

(4)
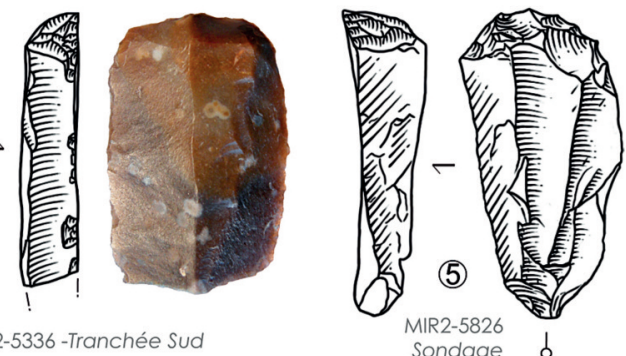

\$ MIR2-5336-Tranchée Sud Sondage
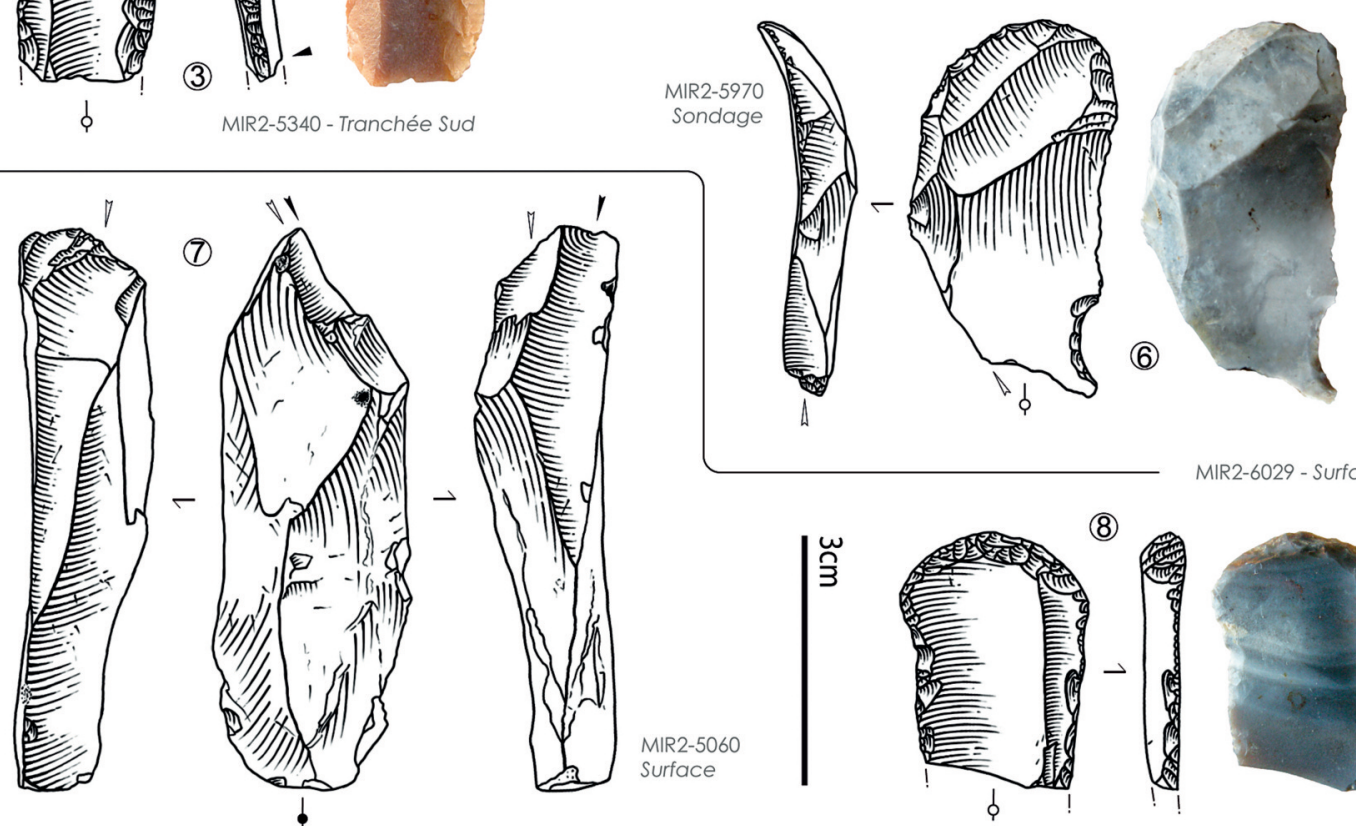

MIR2-6029 - surface
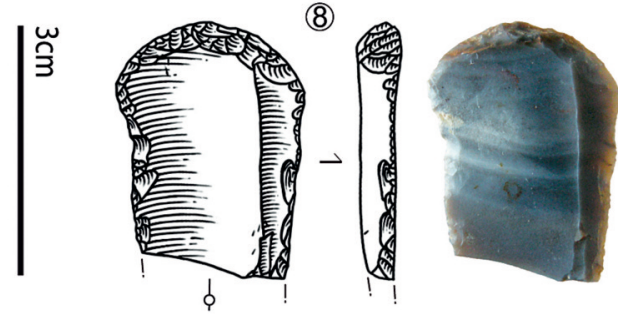

Figure 11 - Exemples d'outils sur lames et supports allongés. $n^{\circ} 1$ : grattoir sur lame large retouchée, percussion tendre minérale (silex allochtone indéterminé, Flysch possible) ; $n^{\circ} 2$ : fragment de support à retouche latérale (silex jaspéroïde tertiaire) ; $n^{\circ} 3:$ fragment de lame à retouches latérales (ancien grattoir ? silex du Bergeracois) ; $n^{\circ} 4$ : grattoir sur lame (silex du Bergeracois) ; $n^{\circ} 5$ : grattoir sur lame (silex tertiaire local) ; $n^{\circ} 6:$ grattoir/bec à retouches alternes sur sous-crête (noter l'aménagement du bec réalisé aux dépens d'un ancien pan de burin ; silex de Chalosse sensu lato); $n^{\circ} 7$ : burin sur éclat laminaire, percussion dure (possible nucléus sur tranche à encoche ; silex tertiaire local) $; n^{\circ} 8$ : grattoir sur lame retouchée issu des ramassages de surface (silex du Fumélois). Dessins C. Fat Cheung, clichés et infographie S. D.

Figure 11 - Tools on blades and elongated blanks. $n^{\circ}$ 1: end-scraper on a wide, retouched blank, soft-stone hammer percussion (undetermined non-local flint, possibly Flysch flint); $n^{\circ} 2$ : fragment of a laterally retouched blank (Jasper-like Tertiary flint); $n^{\circ} 3$ : fragment of a laterally retouched blade (reworked end-scraper? Bergeracois flint); $n^{\circ} 4$ : endscraper on a blade (Bergeracois flint); $n^{\circ} 5$ : endscraper on a blade (local Tertiary flint); $n^{\circ} 6$ : endscraper/alternately retouched bec on a secondary crest (note the installation of the bec from the previous burin removal; Chalosse flint sensu lato); $n^{\circ}$ 7: burin on an elongated blank, hard-hammer percussion (possible core on the edge of a notch; local Tertiary flint); $n^{\circ}$ 8: end-scraper on a retouched blade (surface-find, Fumelois flint). Drawings C. Fat Cheung, photos and illustration $S$. D. 

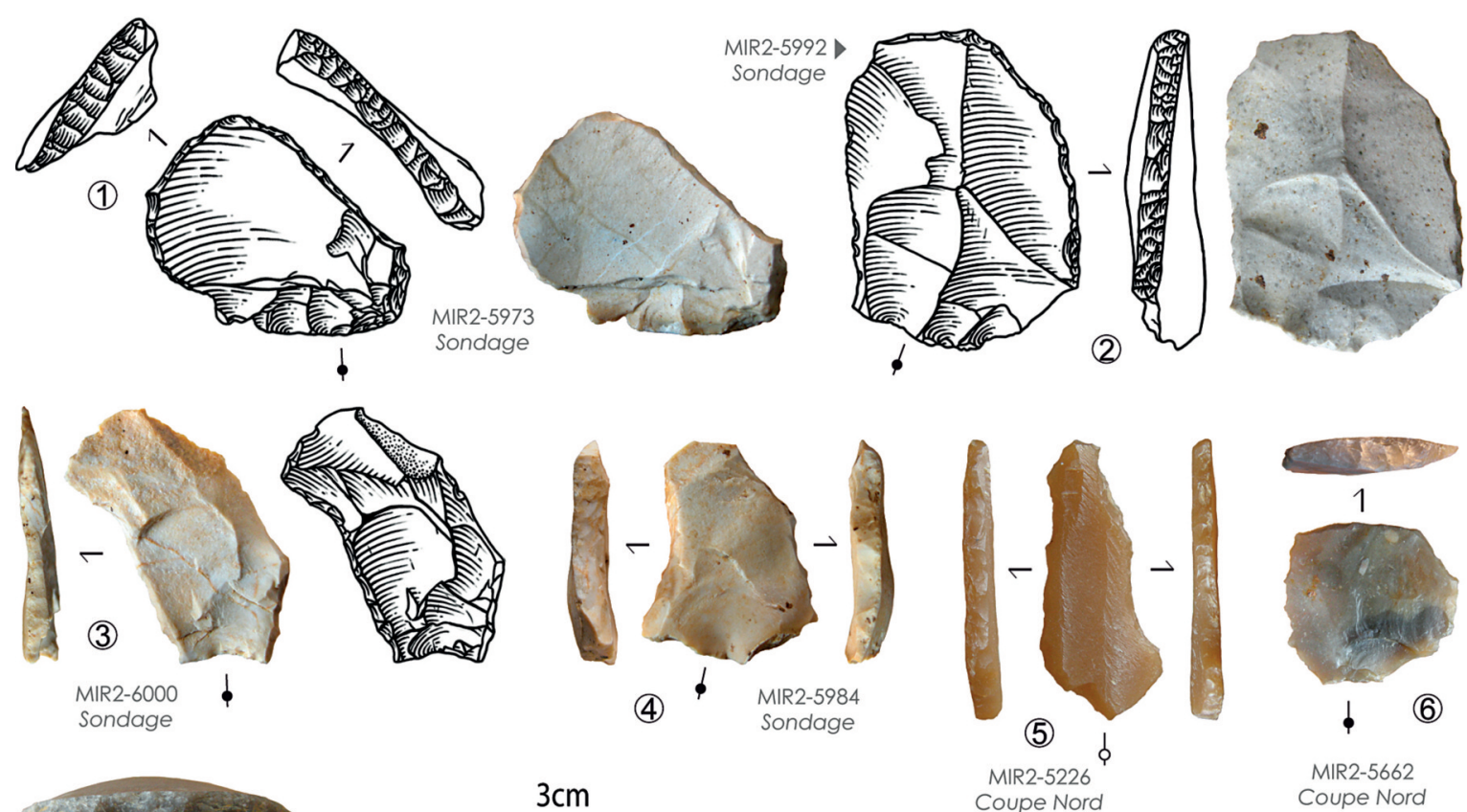

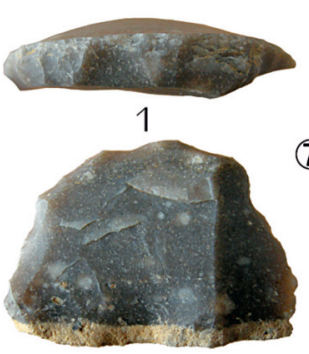

l
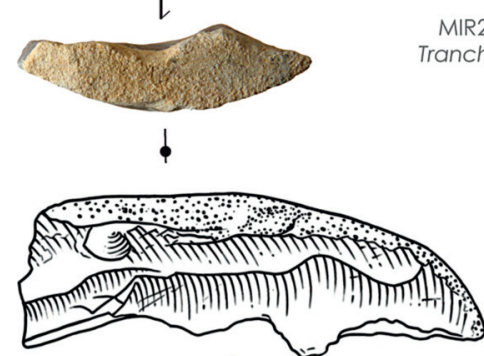

1

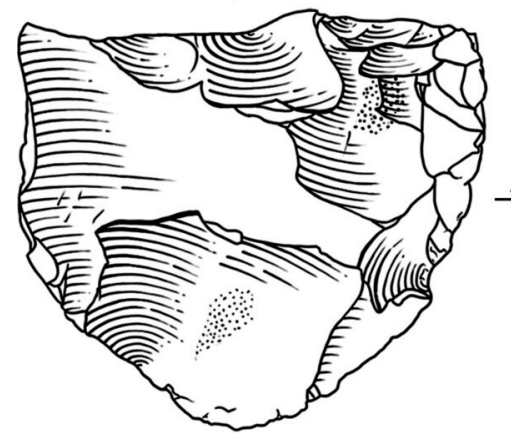

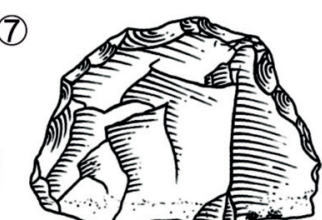

MIR2-5105

Tranchée Sud
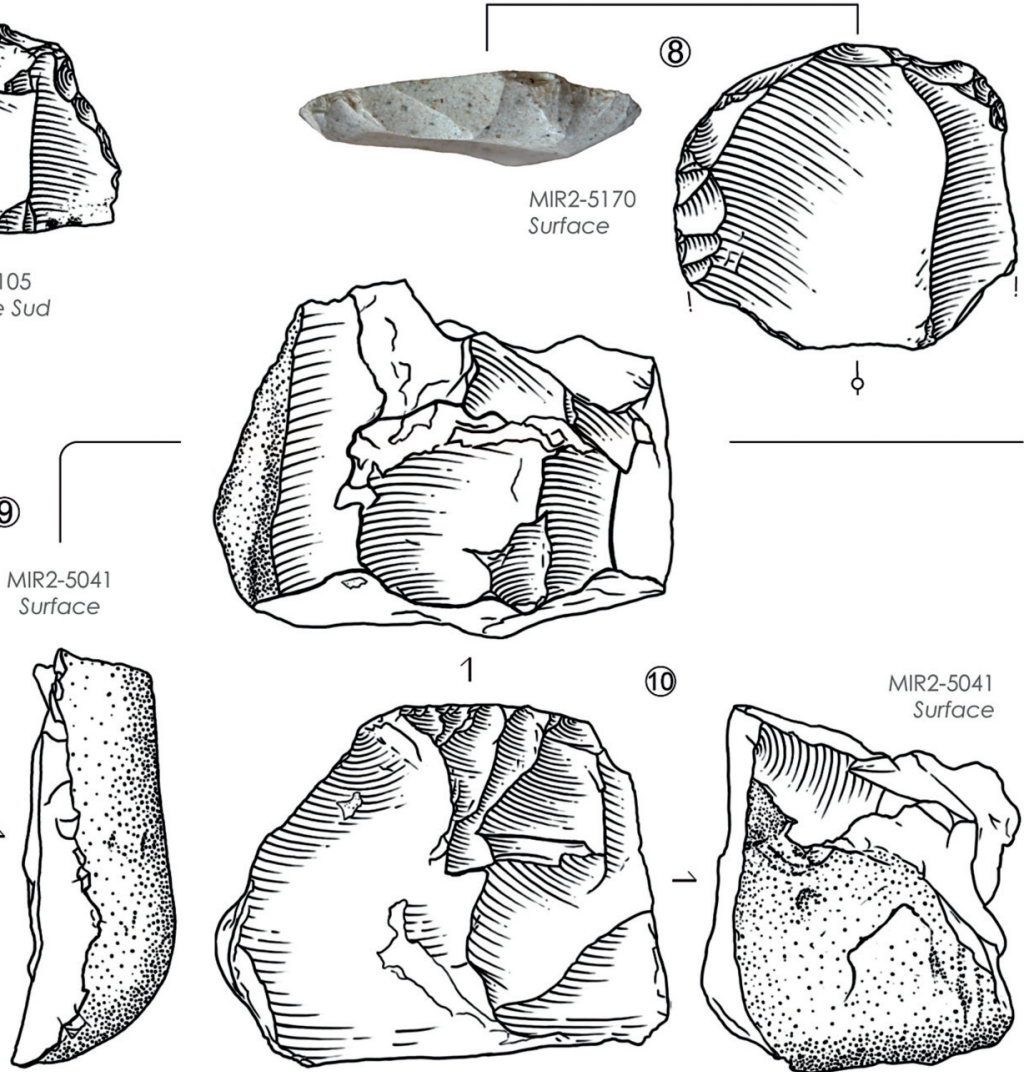

Figure 12 - Raclettes issues des différents secteurs de fouille ( $n^{\circ s} 1$ et 3 : silex tertiaire local ; $n^{\circ} 2$ et $6:$ silex marins, allochtone indéterminé ; $n^{\circ} 4$ et 5 : silex indéterminés; $n^{\circ} 7$ : silex du Sénonien), grattoir sur éclat ( $n^{\circ} 8$, silex marin, allochtone indéterminé) et nucléus à éclats récoltés en surface ( $n^{\circ s}$ 9-10: silex tertiaire local). Dessins $C$. Fat Cheung, clichés et infographie S. D.

Figure 12 - Raclettes from the different excavation sectors ( $n^{\circ} 1$ and 3: local Tertiary flint; $n^{\circ} 2$ and 6: undetermined non-local marine flint; $n^{\circ} 4$ et 5: undetermined flint; $n^{\circ} 7$ : Senonian flint), endscrapers on flakes ( $n^{\circ} 8$, undetermined non-local marine flint) and flake core ( $n^{\circ} 9$ and 10, surface-finds, local Tertiary flint. Drawings C. Fat Cheung, photos and illustration S. D. 

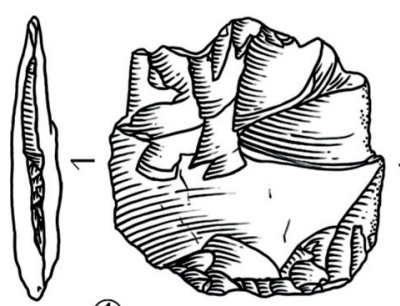

(1)

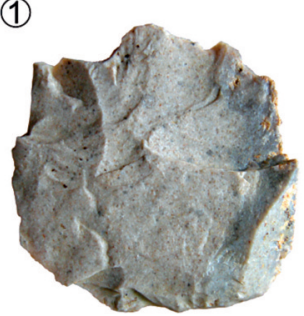

Sondage

$3 \mathrm{~cm}$
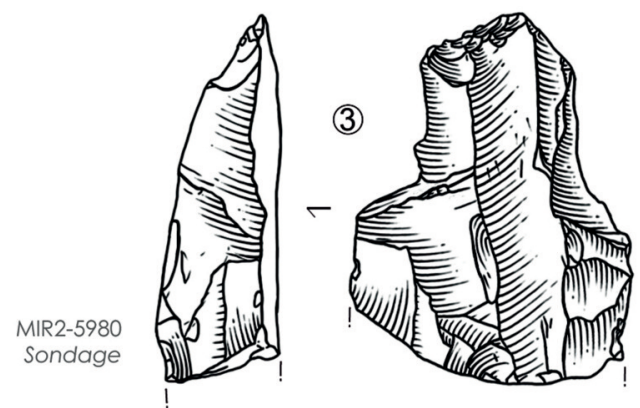

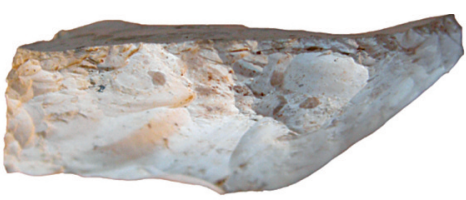

(2)
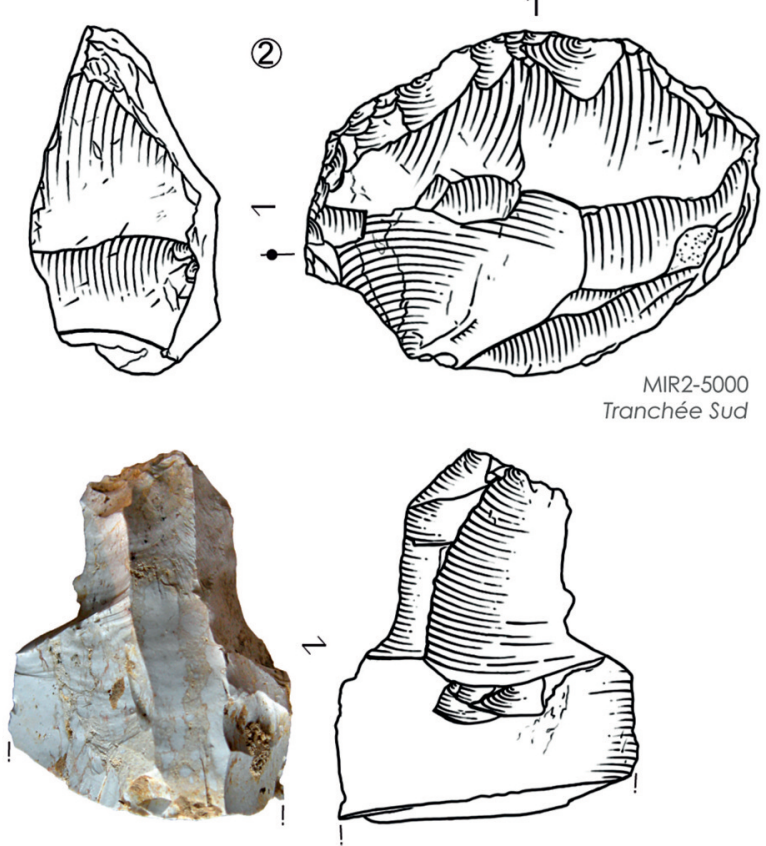

Figure 13 - Exemples de pièces esquillées ( $n^{\circ} 1$ : silex du Sénonien; $n^{\circ} 3:$ silex tertiaire local) et de racloir ( $n^{\circ} 2:$ silex tertiaire local). Dessins C. Fat Cheung, clichés et infographie S. D.

Figure 13 - Splintered pieces ( $n^{\circ}$ 1: Senonian flint; $n^{\circ}$ 3: local Tertiary flint;) and a scraper ( $n^{\circ} 2$; local Tertiary flint). Drawings $C$. Fat Cheung, photos and illustration S. D.

réalisés en Tranchée Sud et dans la colonne test, il convient de signaler l'existence de trois fragments de microlamelles à dos dextre inverse semi-abrupt (fig. 14, $n^{\circ s}$ 8-10). Ce morphotype, sans doute sous-représenté par les modalités de récolte du matériel, rappelle non seulement certains éléments décrits à Mirande 1 (Bosinski 2013 - p. 159 et obs. pers. ML et SD), mais également certains types de microlithes signalés au sein de plusieurs ensembles lithiques du sud-ouest européen attribués tant au Badegoulien (Lassac, Aude : Sacchi 1986 et Ducasse 2010 - p. 159) qu'au Magdalénien inférieur (Fontgrasse, Gard : Bazile 1989 et Langlais, 2010, p. 90 ; ensemble inférieur de Saint-Germain-la-Rivière, Gironde : Lenoir, Marmier, Trécolle 1991 et Langlais et al. 2015 ; Montlleo, Espagne : Langlais 2010).

Différentes modalités de production lamellaire ont pu être documentées, notamment sur la base de l'analyse des 19 nucléus mis au jour. II s'agit notamment de débitages enveloppants sur rognons à surface de débitage plus ou moins cintrée et convergente (fig. $15 \mathrm{n}^{\text {os }} 2$ et 3 ) mais aussi de productions sur éclats (fig. $15 n^{\circ s} 1,4-8$ ). Ces dernières sont exprimées selon diverses modalités. Si la mieux représentée, susceptible d'être notamment à l'origine des supports de microlamelles à dos inverse, correspond à des débitages sur « front dorsal » ( $\left.n^{\circ s} 4-8\right)$, la mise en œuvre de production «sur tranche », plus ou moins enveloppante, est de son côté documentée par le biais de rares nucléus (fig. $15 \mathrm{n}^{\text {os }} 1$ et 9 ) et d'un certain nombre de sous-produits caractéristiques (i.e. éclats lamellaires à pan revers, voire bi-débordants, traduisant dans certains cas la mise en œuvre d'un débitage «préférentiel débordant » : Ducasse et Langlais 2007 ; Ducasse 2010).

\subsection{2 - L'exploitation du quartz}

L'ensemble des quartz provient vraisemblablement de la paléo-terrasse sur laquelle les groupes humains se sont installés. L'examen des pièces récoltées à la fouille a conduit à rejeter plusieurs galets entiers ou fragmentés ne portant aucun stigmate anthropogène certain. Au total, les pièces clairement issues d'un processus de taille ainsi que les fragments et (micro)débris résultant possiblement d'une action anthropique constituent un corpus de 212 vestiges (tabl. 5).

Plusieurs produits (galets, nucléus, éclats), entiers ou fracturés, témoignent de la mise en œuvre d'un débitage par percussion bipolaire sur enclume (fig. 16). Cette méthode, documentée par quelques remontages (fig. 17), constitue le principal mode de fracturation des galets au percuteur dur (nombreux accidents de type Siret : fig. 16 

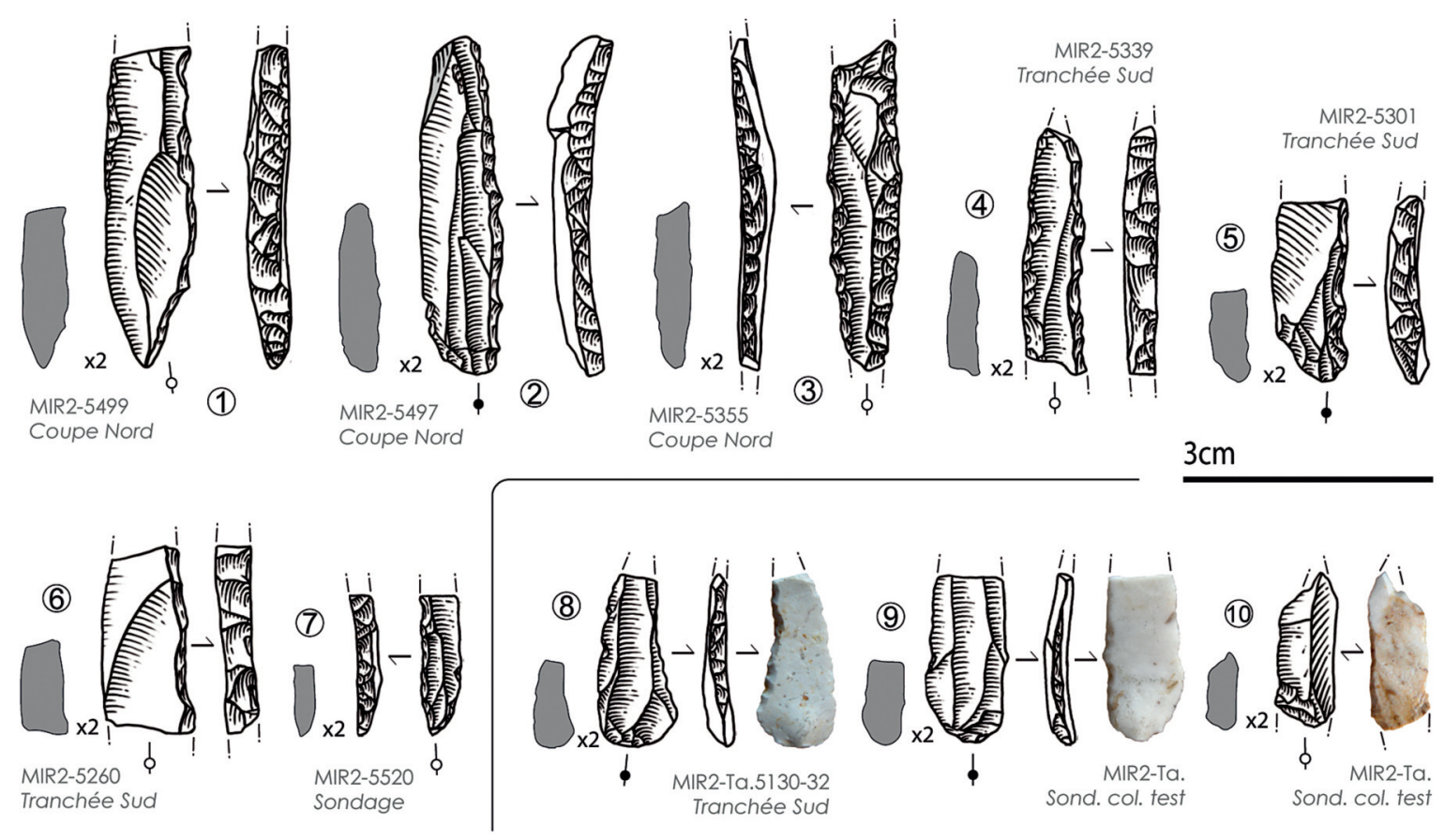

Figure 14 - Lamelles et microlamelles à dos issues des différents secteurs de fouille; $n^{\circ s} 8$-10: microlamelles à dos inverse récoltées lors des tests de tamisages ( $n^{o s} 2,5,7$ et 8 : silex tertiaire ; $n^{\circ} 3$ : silex du Fumélois ; $n^{\circ s} 1,6,9$ et 10 : indéterminés). Dessins C. Fat Cheung, clichés et infographie $S$. D.

Figure 14 - Bladelets and backed micro-bladelets from the different excavated sectors ( $n^{\circ} 2,5,7$ and 8: Tertiary flint; $n^{\circ} 3:$ Fumelois flint; $n^{\circ}$ 1, 6, 9 and 10: undetermined raw materials). Drawings C. Fat Cheung, photos and illustration S. D.

$\mathrm{n}^{\circ}$ 2) afin d'obtenir des supports. Deux galets présentent des stigmates d'utilisation comme percuteur et, parmi ceuxci, deux ont été repris par débitage sur enclume (fig. 18 $n^{\circ}$ 1). L'hypothèse de recyclages de macro-outils en volumes à débiter est donc concrètement envisageable. Parmi les 18 pièces considérées comme des nucléus débités sur enclume, certaines correspondent à des éclatsmatrices résultant eux-mêmes d'un débitage de ce type. On peut donc envisager que certains gros galets aient été d'abord fracturés sur enclume afin de créer des surfaces propices à une poursuite du débitage aux dépens du galet, mais également de produire de grands supports destinés à être eux-mêmes utilisés en tant que volumes à débiter. Le débitage bipolaire sur enclume est généralement réalisé dans l'épaisseur du galet et peut ensuite se poursuivre aux dépens d'une nouvelle surface adjacente à la première. L'examen des talons et celui des corniches de nucléus montre l'absence de préparation des plans de frappe avant extraction des produits.

Conjointement à ce mode dominant de fracturation, seuls trois éclats ainsi qu'un fragment de nucléus pourraient témoigner de la mise en œuvre d'un second procédé de débitage mettant cette fois en jeu une percussion tangentielle (fig. $18 \mathrm{n}^{\circ \mathrm{s}} 3$ et 4). II semble donc que l'on ait affaire à une imbrication de gestes techniques (percussion bipolaire sur enclume ou tangentielle) qui participent à la fracturation de galets en quartz issus de la paléo-terrasse. L'objectif économique semble être la production de supports tranchants dont l'utilisation pour la boucherie est probable (Bracco et Morel 1998) bien que cette hypothèse ne puisse ici être étayée faute d'objets clairement utilisés et en l'absence d'une étude fonctionnelle. En outre, l'unique pièce portant des retouches latérales nettes, assimilable à une partie active de racloir (fig. $18 n^{\circ} 2$ ), correspond à un fragment dont l'origine technologique reste indéterminée.

\subsection{3 - Les autres roches}

Parmi les autres roches $(\mathrm{N}=4)$, on peut noter la présence de trois vestiges apparentés à la famille des trachytes et qui témoignent d'une utilisation en macro-outils ou d'une exploitation en volume à débiter des éclats. Si, en l'absence d'objectifs clairs, cette dernière hypothèse reste délicate à envisager, l'agencement des négatifs visibles sur certaines pièces permet de proposer l'hypothèse de volumes calibrés par des enlèvements périphériques, et ce pour une fonction qui nous échappe (outils dormants ?), notons qu'aucun stigmate ne suggère leur emploi comme enclume. Signalons enfin la présence d'une plaquette de calcaire présentant des stigmates compatibles avec une utilisation en retouchoir ou petit percuteur.

\section{3 - Synthèse et discussion}

L'opération de terrain menée à Mirande 2 apporte plusieurs informations inédites, et ce à différentes échelles spatiotemporelles. 


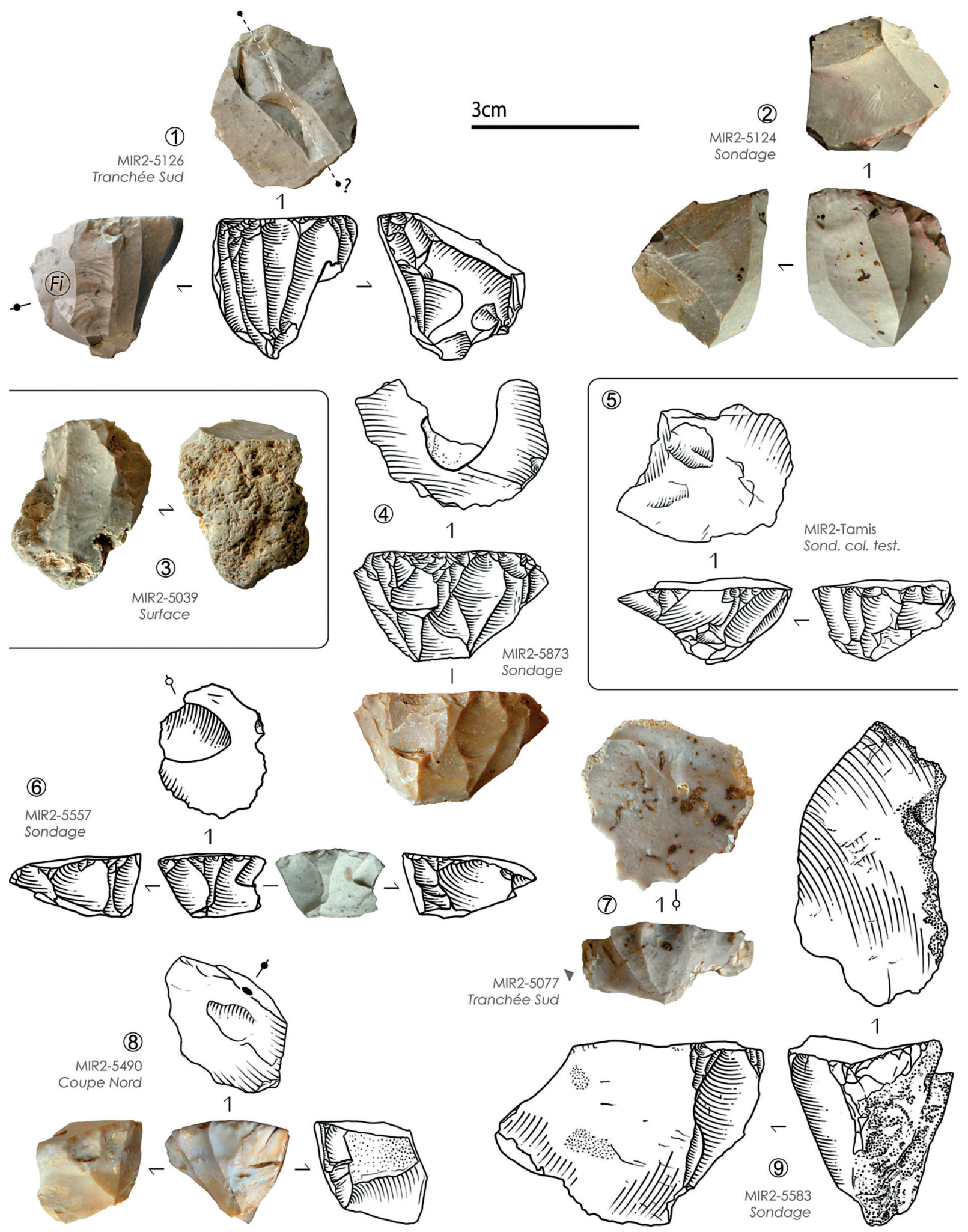

Figure 15 - Exemples de nucléus lamellaires et microlamellaires (silex tertiaire, excepté $n^{\circ} 4$ : indéterminé). Noter l'éclat-support du nucléus $n^{\circ} 1$, potentiellement issu d'une production sur enclume ( $F i$ : face inférieure; le plan de frappe et le flanc gauche correspondant aux deux pans de la face supérieure). Dessins $C$. Fat Cheung, clichés et infographie $S$. $D$.

Figure 15 - Bladelets and micro-bladelet cores (Tertiary flint excepted $n^{\circ} 4$ : undetermined). Note the blank of core on flake $n^{\circ} 1$, possibly extracted on anvil). Drawings C. Fat Cheung, illustration S. D. 


\section{$3 \mathrm{~cm}$}

(1)

MIR2-5753

Tranchée Sud
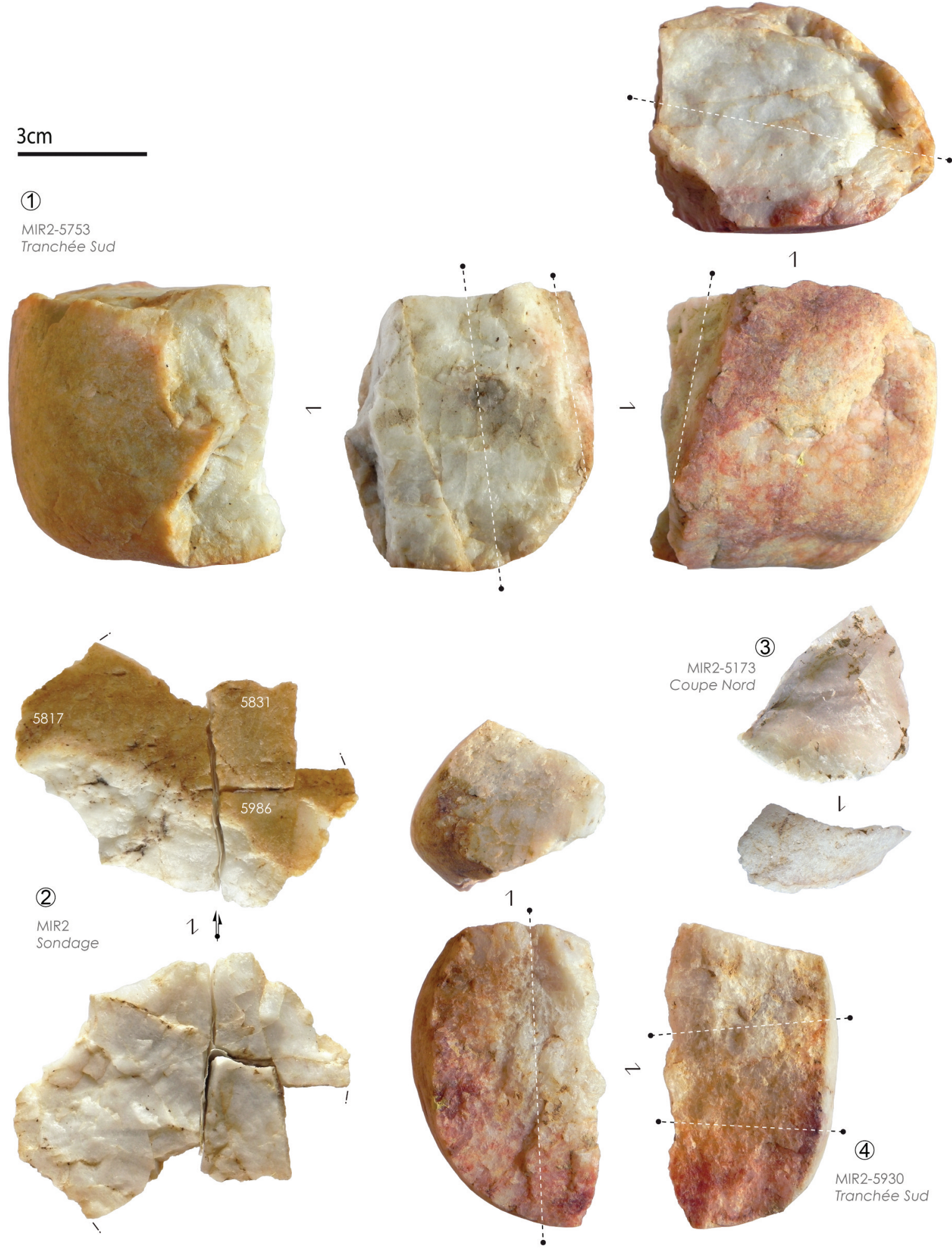

Figure 16 - Nucléus et produits issus de l'exploitation sur enclume des quartz de la paléo-terrasse ( $n^{\circ} 1$ et 4 : nucléus ; $n^{\circ} 2$ : raccord d'un éclat semi-cortical à talon esquillé/écrasé et fracture Siret ; $n^{\circ} 3$ : éclat à talon cortical ; les lignes tiretées indiquent les principaux axes de percussion). Clichés M. L., infographie S. D.

Figure 16 - Cores and products from bipolar percussion of quartz from the paleo-terrace $\left(n^{\circ} 1\right.$ and 4 : cores; $n^{\circ} 2$ conjoin of a semicortical flake with a crushed/splintered butt to a Siret fracture; $n^{\circ} 3$ flake with a cortical butt; the dashed line indicates the main percussion axes) Photos M.L., Layout S.D. 

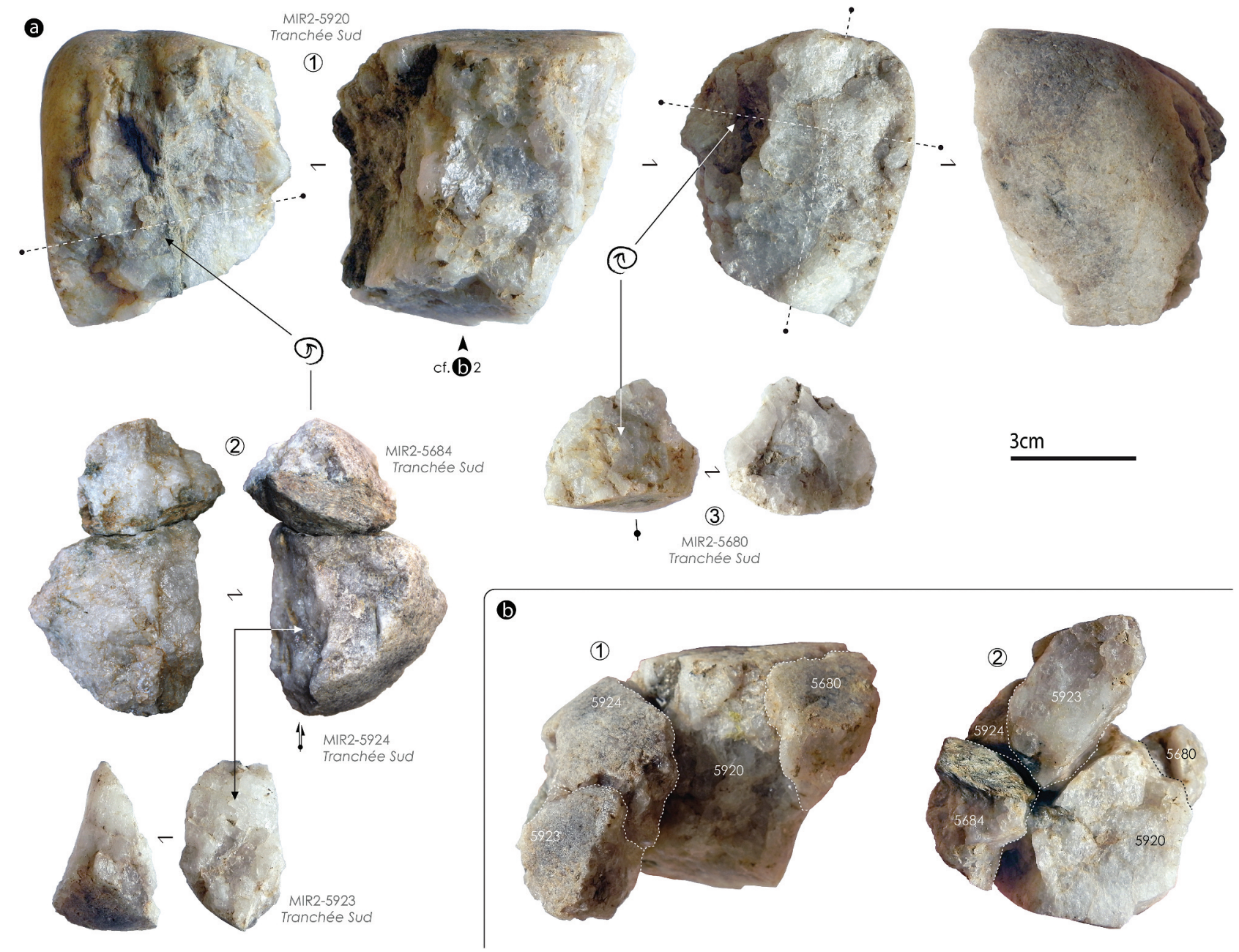

Figure 17 - Remontage partiel d'une séquence de débitage sur enclume à partir d'un galet de quartz issu de la Tranchée Sud (a : éclaté du remontage ; $b$ : vues des différents éléments remontés; les lignes tiretées indiquent les principaux axes de percussion). Clichés M. L., infographie S. D.

Figure 17 - Partial refit of a bipolar percussion reduction sequence of a quartz pebble from the South Trench (a: before refitting, $b$ : different views of the refit elements; dashed lines indicate the main percussion axes); Photos M.L. Layout, S.D.

Du point de vue de la géologie locale, elle permet de proposer un calage chronologique de la basse terrasse de l'Aveyron (Fy2) qui rejoint les résultats obtenus par J.-P. Texier (2014) dans son étude géologique de l'abri Gandil, situé à une dizaine de kilomètres à l'est. À Mirande 2, la plupart des vestiges archéologiques proviennent d'une unité graveleuse interprétée comme résultant de la mise en place de la terrasse Fy2. Étant donné l'intervalle d'âge que l'on peut donner au mobilier attribué au Badegoulien (ca 23-21 ka cal. BP), la phase finale de mise en place de cette terrasse pourrait donc correspondre à la fin du Pléniglaciaire supérieur.

Du point de vue archéologique, le gisement de Mirande 2 témoigne d'une (ou plusieurs) occupation(s) badegoulienne(s) sur une ancienne terrasse de l'Aveyron, à proximité de sa confluence avec le Gouyré. Inédit dans cette zone géographique, l'ensemble lithique mis au jour se caractérise par l'exploitation marquée des matériaux locaux (silex et quartz) mais aussi par l'apport de silex issus de territoires parfois éloignés, connectant Mirande 2 avec le nord et le sud-ouest du Bassin aquitain. Les productions en silex sont matérialisées par une variété d'objectifs et de modalités techniques (débitages laminaires et lamellaires, productions d'éclats). De son côté, le corpus de microlithes lamellaires rappelle notamment les résultats obtenus sur d'autres gisements de plein air badegouliens comme Lassac (Sacchi 1986 ; Ducasse 2010) ou Oisy (Bodu, Chehmana, Debout 2007). L'exploitation du quartz permet de produire des éclats ou des blocs secondaires par le biais d'une fracturation bipolaire sur enclume de galets issus de la paléo-terrasse. Ce comportement technique rappelle 

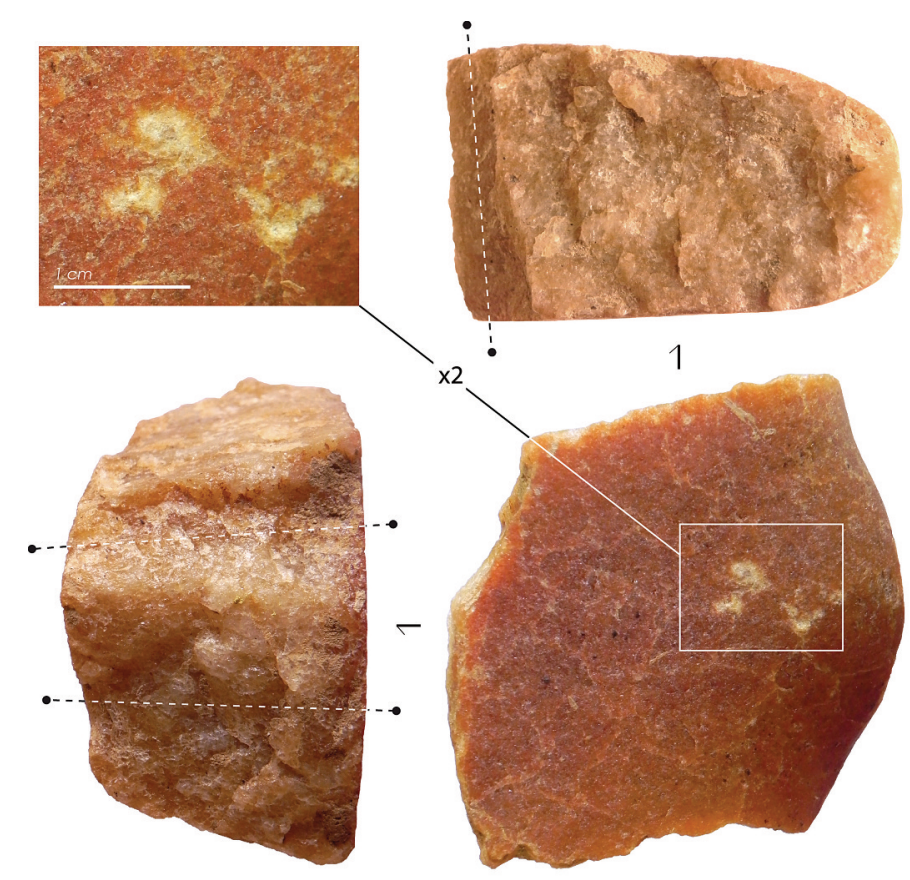

$$
3 \mathrm{~cm}
$$

(1)

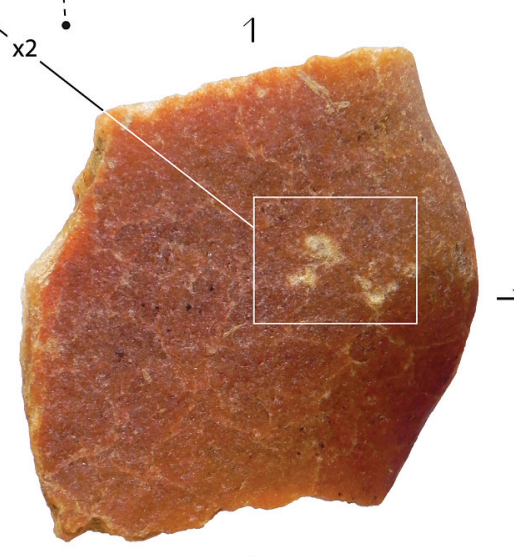

l

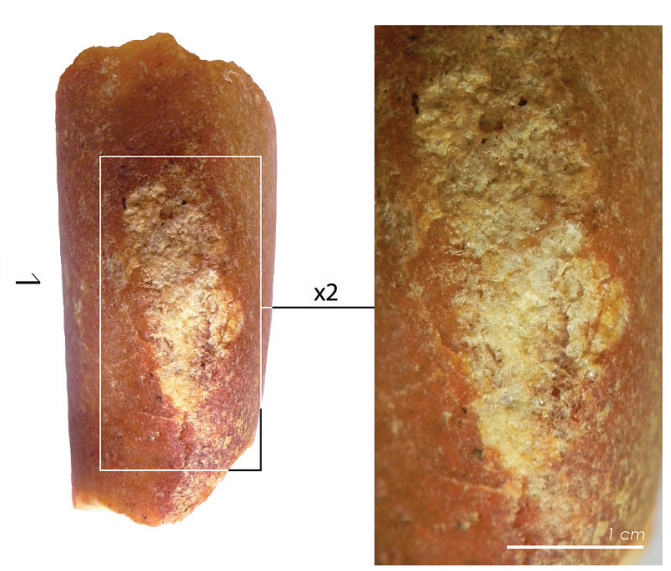

MIR2-5561 Sondage
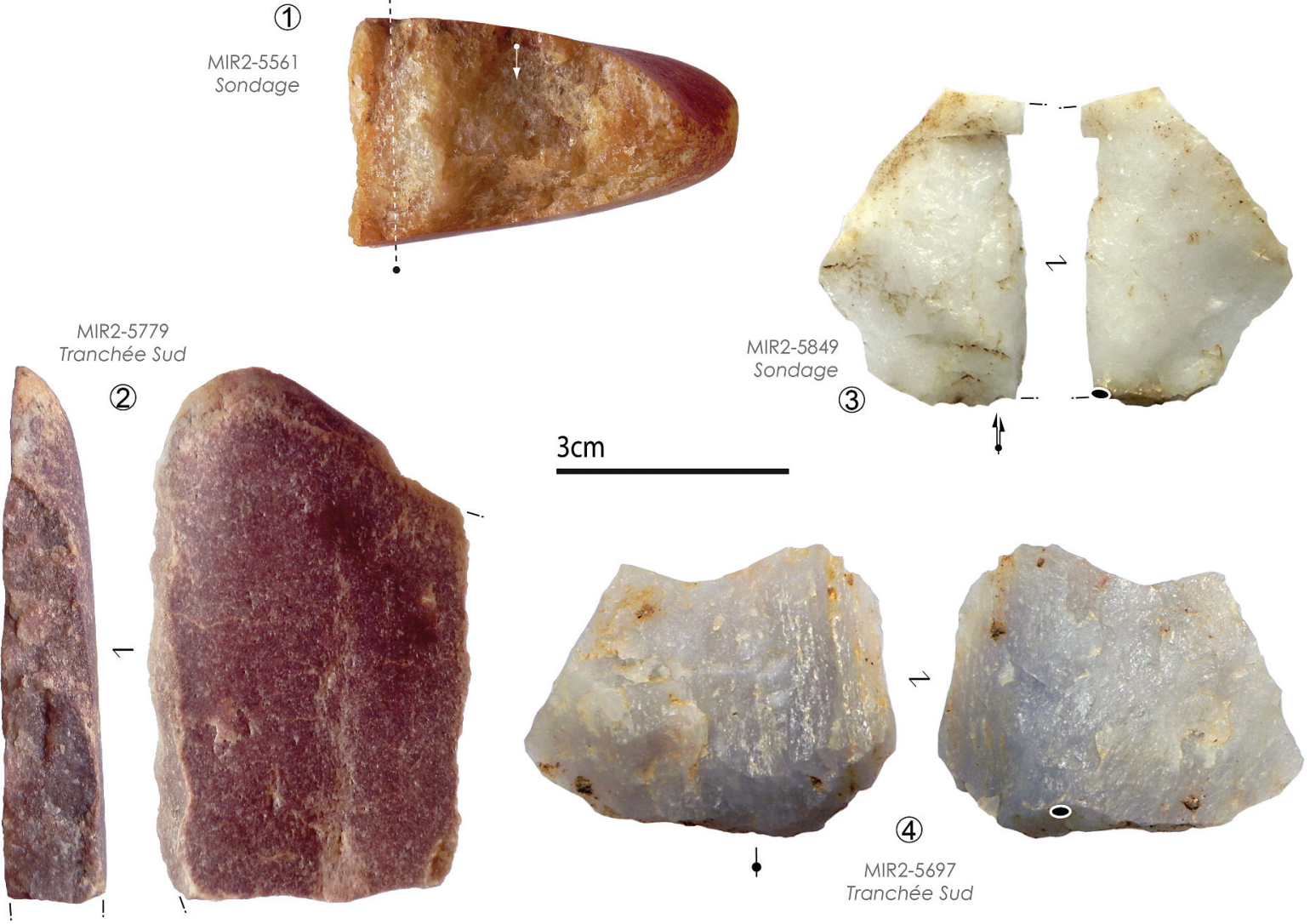

$3 \mathrm{~cm}$
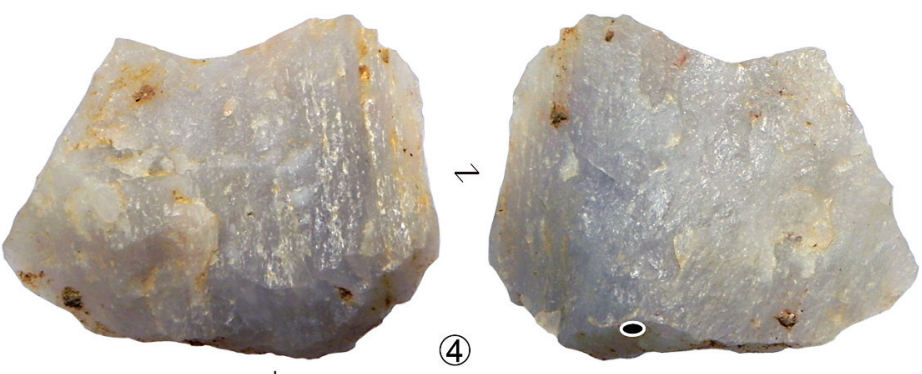

MIR2-5697

Tranchée Sud

Figure 18 - $n^{\circ} 1$ : exemple d'un macro-outil (percuteur) probablement « recyclé » en volume à débiter (débitage bipolaire sur enclume ; les lignes tiretées indiquent les principaux axes de percussion ; échelle à $75 \%$ ), $n^{\circ} 2$ : fragment à retouche latérale continue (racloir), $n^{\circ s} 3$ et 4 : éclats probablement extraits par percussion lancée tangentielle. Clichés M. L., infographie S. D.

Figure 18 - $n^{\circ}$ 1: heavy-duty tool (hammerstone) probably recycled as a core (bipolar percussion on an anvil ; the dashed lines indicate the main percussion axes, $3 / 4$ scale), $n^{\circ} 2$ : fragment with continuous retouch (scraper), $n^{\circ s} 3$ and 4 : flakes probably detached by freehand percussion with a tangential blow. Photos M.L. Layout, S.D. 
fortement ce qui a pu être décrit à Mirande 1 (Bosinski et Guicharnaud 2008). Si les gisements du Paléolithique supérieur où ces productions en quartz ont été précisément documentées (Bracco 1996, 1997) restent rares, le locus badegoulien de La Roche à Tavernat (Chanteuges, HauteLoire) y tient une place particulière. Ce gisement a en effet livré une abondante série de quartz dont l'analyse a permis de documenter l'existence d'une chaîne opératoire de production d'éclats par percussion posée sur enclume, ceci pour fractionner certains gros blocs en supports de nucléus (Bracco 1993 ; Bracco et Slimak 1997). Bien que cette modalité de fracturation de galets sur enclume pour obtenir des volumes à débiter soit également connue dans d'autres contextes (e.g. Soriano et al. 2009), ces premières comparaisons nous conduisent à réinterroger le site de Mirande 1.

L'assemblage lithique de Mirande 2 présente de fortes similitudes avec son voisin Mirande 1 mais aussi les couches basales de l'abri Gandil (c.23-25) tous deux attribués au Magdalénien inférieur (Langlais et al. 2007 ; Ladier dir. 2014). C'est en outre l'absence de certaines modalités opératoires lamellaires (i.e. productions « sur front ventral déjeté »: Ducasse et Langlais 2007 ; Langlais et Ducasse 2013) conjointement à la présence de raclettes qui permettent de distinguer le Badegoulien de Mirande 2 du Magdalénien inférieur des sites voisins. La consultation préalable de la thèse de B. Pajot (1968) laissait entrevoir l'existence possible de raclettes parmi les collections de ramassage Bergougnoux/Chaillot et Pajot - pièces classées dans les «lames et éclats tronquées 》 (ibid. fig. 146, p. 297, n 4 et 5). Toutefois, l'examen récent d'un lot d'outils issu des collections Guicharnaud ne nous a pas permis de confirmer ce diagnostic. Dès lors, plusieurs questions se posent sur les relations entretenues entre les deux « sites " et, ce faisant, sur le sens à donner à l'absence de raclettes à Mirande 1 (problème de diagnose ? Sectorisation des activités pour une même occupation badegoulienne ? Distinction chrono-culturelle ? etc.). En revanche, la diversité des modalités de production lamellaire exprimée à Mirande 1 (Bosinski, Guicharnaud, Morala sous presse) et, notamment, la présence de nombreux éléments témoignant d'un débitage (micro)lamellaire sur tranche d'éclat de type «préférentiel débordant» (Ducasse et Langlais 2007 ; Ducasse 2010 ; Ducasse et Langlais 2017) accentue une fois encore les filiations techniques entre Badegoulien et Magdalénien inférieur (ibid.).

Ainsi, l'ensemble des données acquises à l'occasion de l'opération de sauvetage menée à Mirande 2 permet non seulement de réinterroger le gisement princeps de Mirande 1 et son attribution chronoculturelle, mais également d'alimenter, au-delà du cadre strictement régional, nos réflexions sur la transition badegoulomagdalénienne.

\section{Remerciements}

Cette opération a été rendue possible grâce à l'autorisation du propriétaire, J.-F. Henri que nous remercions vivement.
Un grand merci également, en dehors des auteurs, aux collègues venus prêter main forte lors de cette opération « commando » : J.-Ch. Castel, C. Fat Cheung, M. Grubert, E. Ladier et M. Paillé. Nous remercions également V. Laroulandie et A. Royer pour leur détermination des restes de faune intrusifs de Mirande 2 et B. Gravina pour la traduction. Nous tenons enfin à remercier G. Bosinski, K. Mussfeldt, E. Ladier, A. Bergeret et E. Pignol pour leur accueil chaleureux à Saint-Antonin-Noble-Val et Montauban lors de la consultation du matériel de Mirande 1. Nous remercions enfin les deux rapporteurs pour leurs remarques constructives.

\section{Références bibliographiques}

ASTRUC J., CUBAYNES R., DURAND-DELGA M., LEGENDRE S., MURATET B., PAJOT B., PELISSIE T., REY J., SIGE B. 2000 - Notice explicative, carte géologique de la France (1/50000), feuille Negrepelisse (931). Orléans: BRGM.

ALLARD M. 2009 - Présentation du site des Peyrugues, Préhistoire du Sud-Ouest 17-2, p. 143-149.

BAZILE F. 1989 - L'industrie lithique du site de plein air de Fontgrasse (Vers Pont-du-Gard, Gard) : sa place au sein du Magdalénien méditerranéen. In : Le Magdalénien en Europe. La structuration du Magdalénien, Actes du colloque de Mayence organise dans le cadre du $\mathrm{Xl}^{\mathrm{e}}$ congrès de I'U.I.S.P.P., 1987, E.R.A.U.L, 38, p. 361-377.

BERGOUGNOUX A. et CHAILLOT M. 1933 - La station préhistorique de Montricoux (Tarn-et-Garonne), Bulletin de la société Archéologique du Tarn-et-Garonne, t.51, p. 119.

BODU P., CHEHMANA L., DEBOUT G. 2007 - Le Badegoulien de la moitié nord de la France. Bulletin Société Préhistorique Française, 104 (4), p. 661-679.

BON F., CHAUVAUD D., DARTIGUEPEYROU S., GARDERE Ph., KLARIC L., MENSAN R. 2002 - Les ressources en silex de la Chalosse centrale : gîtes et ateliers du dôme diapir de Bastennes-Gaujacq et de l'anticlinal d'Audignon, In : N. Cazals (dir.) Comportements techniques et économiques des sociétés du Paléolithique supérieur dans le contexte pyrénéen. Projet Collectif de Recherche 2002, Service Régional de l'Archéologie de Midi-Pyrénées, p. 47-63.

BOSINSKI G. 2013 - Les microlithes de Mirande. In : S. Ducasse et C. Renard (coord.), Sur l'évolution de l'organisation socio-économique des groupes humains entre la fin du Solutréen et les débuts du Magdalénien. Des Causses du Quercy aux contreforts pyrénéens entre 23500 et $18500 \mathrm{cal}$. BP. Rapport annuel de PCR, Service Régional de l'Archéologie Midi-Pyrénées, Toulouse, p. 151-166.

BOSINSKI G., GUICHARNAUD R. 2008 - The working of quartz at the Magdalenian site of Mirande, commune de Nègrepelisse (Tarn-et-Garonne, France). In : Z. Sulgosotowska et A.-J. Tomaszewski (ed.), Man - 
Millenia - Environment. Studies in honor of Professor Schild, p. 253-262.

BOSINSKI G., GUICHARNAUD R., MORALA A. sous presse - Le site de Mirande, commune de Nègrepelisse (Tarn-et-Garonne), Préhistoire du Sud-Ouest.

BRACCO J-P. 1993 - Mise en évidence d'une technique spécifique pour le débitage du quartz dans le gisement de la Roche à Tavernat (Massif central, France), Préhistoire Anthropologie Méditerranéenne, 2, p. 43-50.

BRACCO J-P. 1996 - Le débitage du quartz dans le Paléolithique supérieur d'Europe occidentale: aspects technologiques et comportementaux, In : S. Miliken \& M. Peresani eds., Lithic Technology. From raw material procurement to tool production, XIIle Congrès UISPP, Forli 1996, workshop 12, p. 81-90.

BRACCO J-P. 1997 - L'utilisation du quartz au Paléolithique supérieur: quelques réflexions technoéconomiques, Préhistoire Anthropologie Méditerranéenne, 6, p. 285-288.

BRACCO J-P., SLIMAK L. 1997 - L'exploitation du quartz dans le Badegoulien de la Roche à Tavernat-Locus I (Haute-Loire, France), Préhistoire Anthropologie Méditerranéenne, 6, 305-315.

BRACCO J-P., MOREL P. 1998- Outillage en quartz et boucherie au Paléolithique supérieur : quelques observations expérimentales. In : Economie préhistorique: les comportements de subsistance au Paléolithique. XVIII Rencontres internationales d'Archéologie et d'Histoire D'Antibes, Ed. APDCA, pp. 387-395, 3 fig.

BRACCO J.-P., MORALA A., CAZALS N., CRETIN C., FERULLO O., FOURLOUBEY Ch. et LENOIR M. 2003 Peut-on parler de débitage discoïde au Magdalénien ancien / Badegoulien : présentation d'un schéma opératoire de production d'éclats courts normalises. In : Peresani M. dir., Discoid lithic technology: advances and implications, B.A.R. international series, p. 83-115.

CASTEL J.-C., CHAUVIERE F.-X., L'HOMME, X., BERTRAN P., DAULNY L., DEFOIS B., DUCASSE S., LANGLAIS M., MANCEL D., MORALA A., RENARD C., TURQ A. 2005 - Le Petit Cloup Barrat (Cabrerets, Lot): Un nouveau site du Paléolithique supérieur récent sur les plateaux du Quercy. Préhistoire du Sud-Ouest 12 (1), p. 91-92.

CAZALS N. 2000 - Constantes et variations des traits techniques et économiques entre le Magdalénien “ inférieur » et « moyen »: analyse des productions lithiques au nord de la péninsule ibérique. Thèse de Doctorat, Université de Paris I, 2 tomes.

CHALARD P., BRIOIS F., LACOMBE S., SERVELLE Ch., SIMONNET R. 1996 - Lithothèque des matières premières siliceuses. Région Midi-Pyrénées, Projet collectif de recherche, rapport de synthèse 1994-1996, 149 p.
CHALARD P., BON F., BRUXELLES L., DUCASSE S., TEYSSANDIER N., RENARD C., GARDERE P., GUILLERMIN P., LACOMBE S., LANGLAIS M., MENSAN R., NORMAND C., SIMONNET R., TARRIÑO A. 2010 Chalosse Type Flint: Exploitation and Distribution of a Lithologic Tracer during the Upper Paleolithic, Southern France, In : M. Brewer-LaPorta, A. Burke and D. Field eds, Prehistoric mines and quarries, a Trans-Atlantic perspective, SAA Apr 2006, San-Juan, Puerto Rico. Oxbow Books, p. 13-22.

CLOTTES J., GIRAUD J.-P., CHALARD P. (dir.) 2012 Solutréen et Badegoulien au Cuzoul de Vers. Des chasseurs de renne en Quercy, ERAUL 131, Liège, 488 p.

COLONGE D., CHALARD P., BILOTTE M., DUCASSE S., PLATEL J.-P. 2011 - Nouvelle découverte d'un gîte à silex à Lepidorbitoïdes dans le Sud-Ouest de la France (SaintAubin, Gers) et implications archéologiques, Bulletin de la Société Préhistorique Française, 108 (3), p. 561-578.

DELAGNES A, LENOBLE A., HARMAND S., BRUGAL J.Ph., PRAT S., TIERCELIN J. -J., ROCHE Y H. 2006 Interpreting pachyderm single carcass sites in the African Lower and Early Middle Pleistocene record: A multidisciplinary approach to the site of Nadung'a 4 (Kenya), Journal of Anthropological Archaeology, 25, p. 448-65.

DUCASSE S. 2010 - La «parenthèse » badegoulienne : fondements et statuts d'une discordance industrielle au travers de l'analyse techno-économique de plusieurs ensembles lithiques méridionaux du Dernier Maximum Glaciaire. Thèse de Doctorat, université de Toulouse-Le Mirail, $442 \mathrm{p}$.

DUCASSE S., LANGLAIS M. 2017 - Mirande 1 : des industries badegouliennes ? Compte-rendu de diagnostic. In : S. Ducasse et C. Renard (coord.), PCR SaM « du Solutréen au Magdalénien »: changements dans l'organisation socio-économique des groupes humains entre 24 et $19 \mathrm{Ka}$ cal.BP. Rapport annuel de PCR, Exercice 2016, Service régional de l'Archéologie Midi-Pyrénées, décembre 2016.

DUCASSE S., LE TENSORER J.M. (dir.) avec la collaboration de CASTEL J.C., CHAUVIĖRE F.X., CRETIN C., FERULLO O., MORALA A., PÉTILLON J.-M. 2016 - La séquence solutréo badegoulienne de la grotte de Cassegros : réévaluation collective et interdisciplinaire d'une séquence de référence pour le Dernier Maximum Glaciaire dans le sud-ouest français. Rapport annuel de PCR, Service Régional de l'Archéologie Aquitaine, Bordeaux, $112 \mathrm{p}$.

FERNANDES P. 2012 - Itinéraires et transformations du silex : une pétroarchéologie refondée, application au Paléolithique moyen, Thèse de doctorat, Université de Bordeaux 1, 2 vol., 623 p. 
FOURLOUBEY C. 1998 - Badegoulien et premiers temps du Magdalénien. Un essai de clarification à l'aide d'un exemple : la vallée de l'Isle en Périgord. Paleo, 10, p. 185-209.

GUICHARNAUD R. (1971-1974, 1976 a et b) - Mirande, commune de Nègrepelisse (Tarn-et-Garonne). Rapports de fouilles, DRAC Midi-Pyrénées.

LADIER E. 1995 - L'abri Gandil à Bruniquel (Tarn-etGaronne) Premiers résultats des fouilles récentes. Bull. Soc. Arch. et Hist. de Tarn-et-Garonne CXX, p. 7-26.

LADIER E. 2000 - Le Magdalénien ancien à lamelles à dos de l'abri Gandil à Bruniquel (Tarn-et-Garonne) : étude préliminaire de l'industrie de la C.20. In : G. Pion (dir.), Le Paléolithique supérieur récent : nouvelles données sur le peuplement et l'environnement, table ronde de Chambéry, 1999, Mémoire SPF 28, p. 191-200.

LADIER E. (dir.) 2014 - L'abri Gandil à Bruniquel (Tarn-etGaronne) : un campement magdalénien du temps de Lascaux, Préhistoire du Sud-Ouest, supplément $n^{\circ} 13$, $270 \mathrm{p}$.

LANGLAIS M. 2007 - Dynamiques culturelles des sociétés magdaléniennes dans leurs cadres environnementaux. Enquête sur 7000 ans d'évolution de leurs industries lithiques entre Rhône et Ėbre. Thèse de doctorat en cotutelle avec les universités de Toulouse-Le Mirail et Barcelone, $550 \mathrm{p}$.

LANGLAIS M. 2010 - Les sociétés magdaléniennes de l'isthme pyrénéen. Ed du CTHS, Documents Préhistoriques, 26, Paris, $337 \mathrm{p}$.

LANGLAIS M., LADIER E., CHALARD P., JARRY M., LACRAMPE-CUYAUBERE F. 2007 - Aux origines du Magdalénien quercinois : les industries de la séquence inférieure de l'abri Gandil (Bruniquel, Tarn-et-Garonne), Paleo 19, p. 341-366.

LANGLAIS M., LAROULANDIE V., COSTAMAGNO S., PÉTILLON J.M., MALLYE J.-B., LACRAMPECUYAUBÈRE F., BOUDADI-MALIGNE M., BARSHAYSZMIDT C., MASSET C., PUBERT E., RENDU W., LENOIR M. 2015 - Premiers temps du Magdalénien en Gironde. Réévaluation des fouilles Trécolle à SaintGermain-la-Rivière (France), Bulletin de la Société Préhistorique Française, 112, p. 5-58.

LANGLAIS M. (coord.), DUCASSE S., LACRAMPECUYAUBÈRE F., SITZIA L. 2014 - Un nouveau jalon badegoulien en Bas-Quercy, L'opération de sondage préventif de Mirande 2 (Vaïssac, Tarn-et-Garonne), Rapport final d'opération, DRAC Midi-Pyrénées, SRACP, $54 \mathrm{p}$.

LANGLAIS M. (coord.), DUCASSE S., CONSTANS G., CHALARD P., LACRAMPE-CUYAUBÈRE F., MUTH X. 2015 - Un nouveau jalon badegoulien en Bas-Quercy, L'opération de sondage préventif de Mirande 2 (Vaïssac, Tarn-et-Garonne), Rapport d'APP, DRAC Midi-PyrénéesSRACP, $31 \mathrm{p}$.
LANGLAIS M. et DUCASSE S. 2013 - Badegoulien versus Magdalénien : II - Le Magdalénien inférieur quercinois, In : M. Jarry, J.P. Brugal, C. Ferrier (dir.), Modalités d'occupation et exploitation des milieux au Paléolithique dans le sud-ouest de la France : l'exemple du Quercy, suppl. Paleo $\mathrm{n}^{\circ} 4, \mathrm{XV}^{\mathrm{e}}$ congrès de l'IUSPP, Lisbonne, session C67, septembre 2006, p. 379-394.

LE BRUN-RICALENS F. 1988 - Contribution à l'étude du Paléolithique du Pays des Serres du Bas-Quercy et de l'Agenais entre le Lot et la Garonne, mémoire de DEA, université de Toulouse-Le Mirail.

MILLET-CONTE J.-C. 1994 - Étude de l'industrie lithique du gisement magdalénien de Mirande (commune de Nègrepelisse, Tarn-et-Garonne). Mémoire de Maîtrise, Université de Paris I-Panthéon-Sorbonne, 333 p.

LENOIR M., MARMIER F., TRECOLLE G. 1991 - Données nouvelles sur les industries de Saint-Germain-la-Rivière (Gironde). In : 25 ans d'études technologiques en Préhistoire. Bilan et perspectives, APDCA, Antibes, p. 245-254.

MOEYERSONS, J., NYSSEN J., POESEN, J. DECKERS, J., HAILE M. 2006 - On the origin of rock fragment mulches on Vertisols: A case study from the Ethiopian highlands, Geomorphology 76, 3-4, p. 411-29.

MORALA A. 1980 - Observations sur le Périgordien, l'Aurignacien et leurs matières premières lithiques en HautAgenais, Mémoire EHESS, Toulouse, $181 \mathrm{p}$.

MORALA A. 2013 - Paléolithique supérieur du Quercy ou Paléolithique supérieur en Quercy : quels apports de la lithologie à la question du peuplement ? In : M. Jarry, J.P. Brugal, C. Ferrier (dir.), Modalités d'occupation et exploitation des milieux au Paléolithique dans le sud-ouest de la France : l'exemple du Quercy, suppl. Paleo $\mathrm{n}^{\circ} 4$, $X V^{e}$ congrès de l'IUSPP, Lisbonne, session C67, septembre 2006, p. 271-296.

MOULINE M.P. 1983 - Les accidents siliceux dans les calcaires lacustres du Castrais et de l'Albigeois. Bulletin de la Société Géologique de la France, 25 (1), p. 51-56.

PAJOT B. 1968 - Les civilisations du Paléolithique supérieur du bassin de l'Aveyron. Travaux de l'Institut d'Art Préhistorique XI, Toulouse, 583 p.

POESEN, J., LAVEE H. 1994 - Rock fragments in top soils: significance and processes, Catena, 23, 1-2, p. 1-28.

SACCHI D. 1986 - Le Paléolithique supérieur du Languedoc occidental et du Roussillon. Gallia Préhistoire XXI ${ }^{\ominus}$ suppl., Ed. du CNRS, Paris, 284 p.

SÉRONIE VIVIEN M.-R. (dir.) 1995 - La grotte de Pégourié, Caniac-du-Causse (Lot). Cressensac, Préhistoire quercinoise, suppl. 2, $334 \mathrm{p}$.

SÉRONIE-VIVEN M. et M.-R. 1987 - Les silex du Mésozoïque nord-aquitain : approche géologique de l'étude 
du silex pour servir à la recherche, Bulletin de la Société Linnéenne de Bordeaux, suppl. XV, 135 p.

SÉRONIE-VIVIEN M., SÉRONIE-VIVIEN M.-R., FOUCHER P. 2006 - L'économie du silex au Paléolithique supérieur dans le bassin d'Aquitaine : le cas des silex à lépidorbitoïdes des Pyrénées centrales. Caractérisation et implications méthodologiques, Paleo, 18, p. 193-216.

SORIANO S., ROBERT A., HUYSECOM E. 2009 Percussion bipolaire sur enclume: choix ou contrainte ? L'exemple du Paléolithique d'Ounjougou (Pays Dogon, Mali), In : V. Mourre et M. Jarry (dir.), « Entre le marteau et l'enclume... " La percussion directe au percuteur dur et la diversité de ses modalités d'application, actes de la tableronde de Toulouse, mars 2004, Paleo n spécial, p.123-132.
TEXIER 2014 - Les dépôts du site magdalénien de Gandil à Bruniquel (Tarn-et-Garonne). Dynamique sédimentaire, signification paléoenvironnementale, lithostratigraphie et implications archéologiques. In : L'abri Gandil à Bruniquel (Tarn-et-Garonne) : un campement magdalénien du temps de Lascaux, Préhistoire du Sud-Ouest, suppl. n 13, p. 35-48

TURQ A. 2000 - Paléolithique inférieur et moyen entre Dordogne et Lot, Paleo, suppl. 2, $456 \mathrm{p}$.

TURQ A., MORALA A. 2013 - Inventaire des silicifications du Quercy, de ses marges et des marqueurs lithologiques du nord-est aquitain : synthèse des données, In : M. Jarry, J.P. Brugal, C. Ferrier (dir.), Modalités d'occupation et exploitation des milieux au Paléolithique dans le sud-ouest de la France : l'exemple du Quercy, suppl. Paleo $\mathrm{n}^{\circ} 4$, $\mathrm{XV}^{\mathrm{e}}$ congrès de l'IUSPP, Lisbonne, session C67, septembre 2006, p. 125-146. 
